\title{
Current Trends in the Development of Microwave Reactors for the Synthesis of Nanomaterials in Laboratories and Industries: A Review
}

\author{
Sylwia Dąbrowska ${ }^{1,2, *}$, Tadeusz Chudoba ${ }^{1}$, Jacek Wojnarowicz ${ }^{1}\left(\mathbb{D}\right.$ and Witold Łojkowski ${ }^{1}$ \\ 1 Polish Academy of Sciences, Institute of High Pressure Physics, Sokołowska 29/37, 01-142 Warsaw, Poland; \\ t.chudoba@labnano.pl (T.C.); j.wojnarowicz@labnano.pl (J.W.); w.lojkowski@labnano.pl (W.L.) \\ 2 Faculty of Materials Science and Engineering, Warsaw University of Technology, Wołoska 141, \\ 02-507 Warsaw, Poland \\ * Correspondence: s.dabrowska@labnano.pl; Tel.: +48-512-719-963
}

Received: 28 August 2018; Accepted: 21 September 2018; Published: 27 September 2018

\begin{abstract}
Microwave energy has been in use for many applications for more than 50 years, from communication, food processing, and wood drying to chemical reactions and medical therapy. The areas, where microwave technology is applied, include drying, calcination, decomposition, powder synthesis, sintering, and chemical process control. Before the year 2000, microwaves were used to produce ceramics, semiconductors, polymers, and inorganic materials; in next years, some new attempts were made as well. Nowadays, it has been found that microwave sintering can also be applied to sintered powder and ceramics and is more effective than conventional sintering. Particularly interesting is its use for the synthesis of nanomaterials. This review identifies the main sources of microwave generation, the delivery mechanisms of microwave energy, and the typical designs and configurations of microwave devices, as well as the measurement and construction material problems related to microwave technology. We focus our attention on the configurations, materials, optimized geometries, and solvents used for microwave devices, providing examples of products, especially nanoparticles and other nanomaterials. The identified microwave devices are divided into four groups, depending on the scale, the maximum pressure developed, the highest temperature for sintering, or other special multi-functions. The challenges of using microwave energy for the synthesis of nanopowders have been identified as well. The desirable characteristics of microwave reactors in the synthesis of nanostructures, as well as their superiority over conventional synthetic methods, have been presented. We have also provided a review of the commercial and self-designed microwave reactors, digestors, and sintering furnaces for technology for synthesis of nanomaterials and other industries.
\end{abstract}

Keywords: microwave; synthesis; high pressure; chemical reaction; reactor design; nanomaterials

\section{Introduction}

The rapid development of microwave syntheses technology is visible in the publications trends of the last decade. A search of the word "microwave" and the phrase "microwave, reaction" in the ScienceDirect scientific search engine resulted in 96,173 and 56,715 records, respectively, in all available research fields from 2010 to 2017 (Chart 1). The increasing availability and diversity of microwave equipment have allowed this heating technology to become more and more popular and useful. A breakthrough in microwave technology occurred before 1990, with the advent of the development of controlled equipment using a closed pressure vessel reactor (Milestone, ERTEC). Nowadays, there are plenty of well-known companies offering microwave reactors for a wide variety of applications [1]. Microwave heating technology, when applied to chemical reactions, represents a sustainable "green" 
chemistry by utilizing safer solvents and reaction conditions, minimizing the potential for accidents, preventing the waste of products, and minimizing the time of reactions. For instance, in different microwave frequencies, it is possible to efficiently synthesize nanoparticles at much shorter times than when relying on conventional synthesis, without the use of microwaves [1].

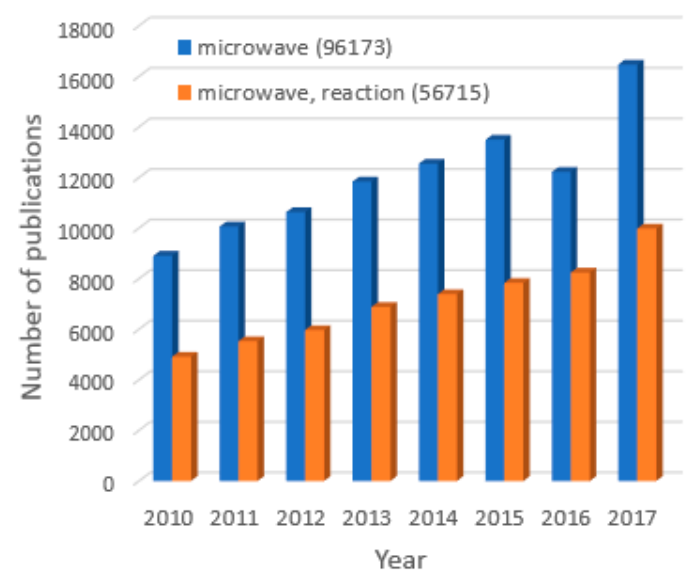

Chart 1. The number of scientific publications published in the period of 2010-2017 identified by a search of the word "microwave" and the phrases "microwave, reaction". Source: ScienceDirect.

The development of the industrial applications of microwave heating, mainly in drying and other thermal treatment processes, was significant, and commercially available on the market from 1967 [2]. Thus, manufacturers quickly found a wide range of applications for microwave technology, thanks to its easy use and low costs. A typical home microwave oven can be easily adapted for use in chemical experiments, and until the 1990s, it was considered the primary model for laboratory equipment manufacturers. However, in a domestic microwave oven, the irradiation power is generally controlled by on- and off-cycles of the magnetron without monitoring the reaction temperature. The lack of temperature and pressure control and even homogenous stirring liquid samples makes performing reproducible chemical synthesis troublesome in such devices. Therefore, in recent years, specialized microwave devices designed for laboratories and industries have been developed.

The main structural materials used in the manufacture of microwave devices are metals, especially steels with high chemical resistance in the form of sheets, screens, and so forth. The close fit of all the metal parts and their grounding and tightness determine the safety of the use, effectiveness, and durability of microwave devices. Heating by microwaves is based on the ability of a particular substance to absorb microwave energy and convert the electromagnetic energy into heat. Every solvent or reagent interacts with microwave energy in different ways. Such interaction depends on the polarity of the solvent, because the microwave heating relies upon the dipole moment of a given molecule; thus, the more polar the reagent, the better the reaction at converting the microwaves into heat $[3,4]$.

Compared with other methods that do not use microwaves, the use of microwave heating improves the homogeneity of the synthesis sludge; the narrow particle size distribution, the smaller size of the particles [1]. In this review, we emphasize the use of microwave reactions and reactors for the development of nanotechnology. Commercial reactors and laboratory reactors as tools for sintering and the synthesis of nanomaterials will also be discussed.

\section{Overview of the Microwave Frequency Effect}

The most common system of microwave generation and transmission is a simple electrical system with a magnetron as the microwave source and a waveguide, a feature commonly adopted in commercial laboratory microwave ovens. A typical magnetron power is ca. $750 \mathrm{~W}$, with an emission efficiency of ca. $85 \%$ and a frequency of $2.45 \mathrm{GHz}$. The power of the heating (e.g., food) is typically controlled by the periodic powering and depowering of the magnetron at a specified interval (e.g., $40 \%$, 
$60 \%, 80 \%$, and $100 \%$ ). The efficiency of the microwave energy transformation into heat emitted in the materials subjected to microwave heating in appropriately designed reactors reaches an even $100 \%$ (according to our own unpublished results). Domestic ovens usually have no measuring devices, and the safety of their operation depends only on their microwave tightness and on maintaining the proper humidity of the heated objects. However, there have been cases where, as a result of uneven heating of ordinary foods, their hot spots get superheated and charred, resulting in the emission of carbon monoxide and other flammable gases, which, when ignited by a spark, may cause an explosion [3]. There are two mechanisms of the microwave heating: dipolar polarization and ionic conduction, in common solvents depending on its molecules, if it is polar or apolar. Polar solvents like ethanol, acetone, water are less transparent for microwaves so their penetration depths are smaller than those of some apolar solvents like benzene or hexane. Many examples are shown by Horikoshi.

The most popular source of microwaves is, therefore, the magnetron operating in the frequency band of $2.45 \mathrm{GHz}[5,6]$. Power sources with different frequencies, ranging from $900 \mathrm{MHz}$ to $10 \mathrm{GHz}$, or with a modulated frequency, are also available [7]. A modern generator allows for the easy adjustment of the emitted power. Magnetrons of $350 \div 1500 \mathrm{~W}$ (household) are used most frequently. The frequency of $2.45 \mathrm{GHz}$, chosen primarily for cooking purposes, is optimum from the point of view of heating substances and objects containing water but is also perfect for heating a range of other substances, such as fats, alcohols, and numerous organic and inorganic solvents.

The industrial, scientific and medical (ISM) radio bands are defined by the International Telecommunication Union Radiocommunications Sector (ITU-R), and they are $2.45 \mathrm{GHz}, 5.80 \mathrm{GHz}$, and $24 \mathrm{GHz}$. Microwave devices can generate frequencies other than $2.45 \mathrm{GHz}$ or $5.80 \mathrm{GHz}$, although they are more expensive compared with those devices operating at commonly known frequencies [8].

\section{Methods of Microwave Energy Generation and Delivery}

The microwave instruments can be classified into two types: monomode (or single mode) and multimode reactors. In monomode reactors, only one reactor vessel can be irradiated; multimode reactors may accommodate several vessels at once, which is not obligatory. For a monomode instrument, a highly homogenous energy field of high-power intensity is provided, resulting in fast heating rates. An instrument with a self-tuning circular waveguide is also available [9] (Figure 1) In monomode cavities, only one mode is present, and the electromagnetic radiation is directed into the reaction vessel and creates a standing wave. Multimode reactors have larger cavities, similar to a domestic microwave oven or digestion systems with microwave diffuser, where the waves are reflected from the walls and distributed in a rather chaotic manner of specific standing wave and oscillating its mode by stirrer. This kind of instrument allows for convenient simultaneous syntheses and can host a few different rotors/sample slots [9-11]. Sometimes, propagating wave is used for processing not only standing waves. In multimode devices, to optimize the homogeneity of the electromagnetic field distribution in the solvent, commercial cavities use a mode stirrer or use turntable reaction places. Ensuring the identical conditions in all vessels is almost impossible; it means that one vessel/sample makes the best result of the energy delivery inside the solution.

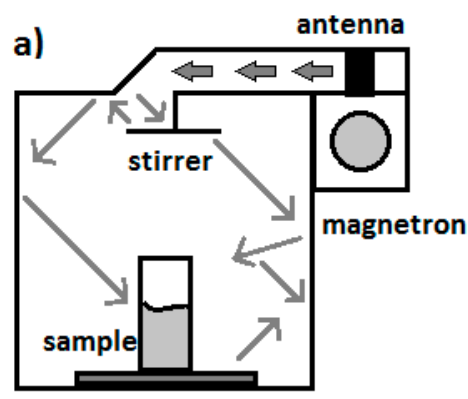

b)

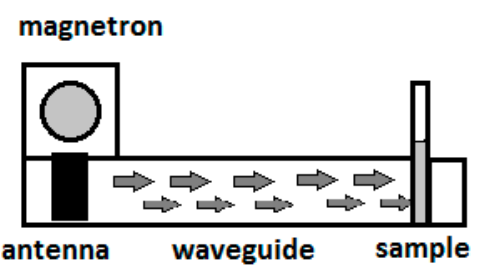

Figure 1. Multimode system (a) and single-mode cavities (b) (source: the IHPP PAS). 
Generator compartments and microwave generators are the part of the equipment dedicated to generating the waves; they consist of a microwave tube (magnetron, klystron, gyrotron, or traveling wave tube (TWT)) or a semiconductor generator together with the power supply unit and eventually, the cooling equipment. The most diffused microwave sources are magnetrons and klystrons thanks to their high output power (for magnetron up to as high as $5 \mathrm{MW}$, used in ship/airplane radars and meteorology) and long lifetime. A klystron is often used in materials processing and the making of dielectric heat. A gyrotron is a high-power linear-beam vacuum tube, which generates millimetric electromagnetic waves by the cyclotron resonance of electrons in a strong magnetic field. The output frequencies range from about $20 \mathrm{GHz}$ to $527 \mathrm{GHz}$, and they are used for many industrial and high-technology heating applications, e.g., in nuclear fusion research experiments to heat plasmas and also in the manufacturing industry as a rapid heating tool in the processing of glass and ceramics, as well as for annealing [12]. The magnetrons used for development and laboratory purposes have an output power of $3000 \mathrm{~W}$ (Figure 2). The typical cause of the end of life of a magnetron is cathode failure; however, the lifetimes of magnetrons have been increasing over the years. Klystrons are less frequently used for chemical reactions, and nowadays, they can be found more in radars, wideband high-power communication television, and radiation oncology. Klystrons are rather expensive for laboratory and industry processing use.

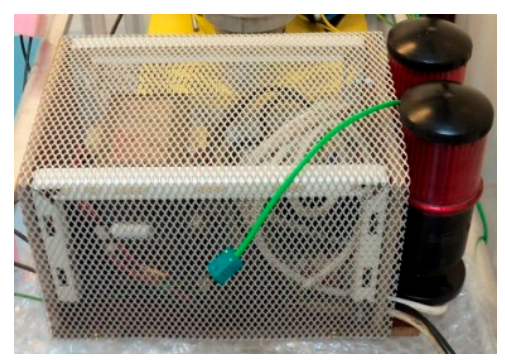

(a)

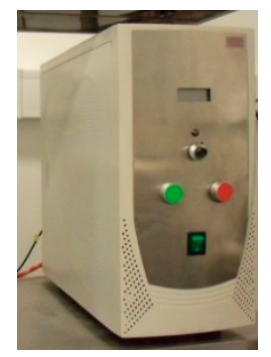

(b)

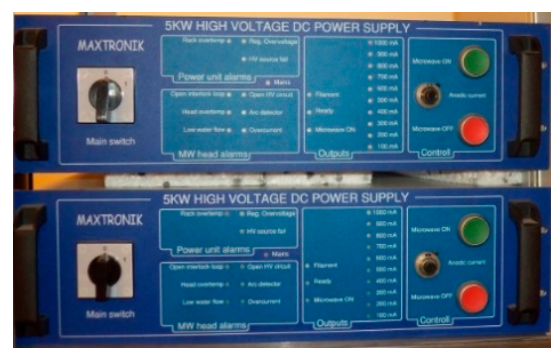

(c)

Figure 2. Examples of supply modules (generators): (a) simple power supplier custom made in our laboratory or experimental work; (b) ERTEC power supplier with a 100-1000 W range; (c) modern ERTEC-MAXTRONIK power supplier with the continuously regulated emitted power of 100-3000 W (IHPP PAS).

Nowadays, a new family of microwave generators is on the market based on GaN semiconductors technology, often indicated as a solid-state source (SSS or S ${ }^{3}$ ) [13]. The lifetime of an SSS generator is longer than magnetrons (lifetime in years); however, at present, the costs of semiconductors are higher, so for laboratory use, there is a significant difference in prices [14]. Semiconductors need a small space for installation; however, there can be a problem cooling this type of generator. The $S^{3}$ technology offers several advantages over magnetrons in various microwave heating applications. The new $S^{3}$ features include frequency and phase variability and control, low input voltage requirements, compactness and rigidity, reliability, and better compatibility with other electronic circuitry (and with the Internet of Things in the future). On the other hand, $\mathrm{S}^{3}$ generators are more sensitive to power reflections, and their efficiency is lower than that of magnetrons. The full utilization of the $\mathrm{S}^{3}$ advantages, especially the frequency variation during the process, requires higher levels of system design and process control [15-17].

\subsection{Local Heating and "Hot Spots"}

The limited microwave penetration depth into various media constitutes an important design limitation of a reactor's dimensions [18]. Figure 3 illustrates the distribution of areas that have been heated more heavily inside samples, and the detected temperature gradients measured using a shielded thermocouple reached $600{ }^{\circ} \mathrm{C}$. The tests were made for a silicon-black carbon mixture. This type of localized overheating, with respect to the rest of the sample's volume, is called a "hot spot". 
In microwave chemistry, a hot spot indicates the inhomogeneous dissipation of MW (microwave) energy through selective heating in different parts of the material due to the uneven distribution of the electromagnetic field within a homogeneous sample. According to our approximate calculations, laboratory reactors with microwave power capabilities of $600 \mathrm{~W}$ can heat $100 \mathrm{~mL}$ containers with water 100 times faster than convection heating, taking into account the thermal conductivity of the vessel's walls and the liquid being heated. Unfortunately, local overheating cannot be studied easily, and currently, its properties can only be understood indirectly by measuring its effects on reaction rates [9-14].

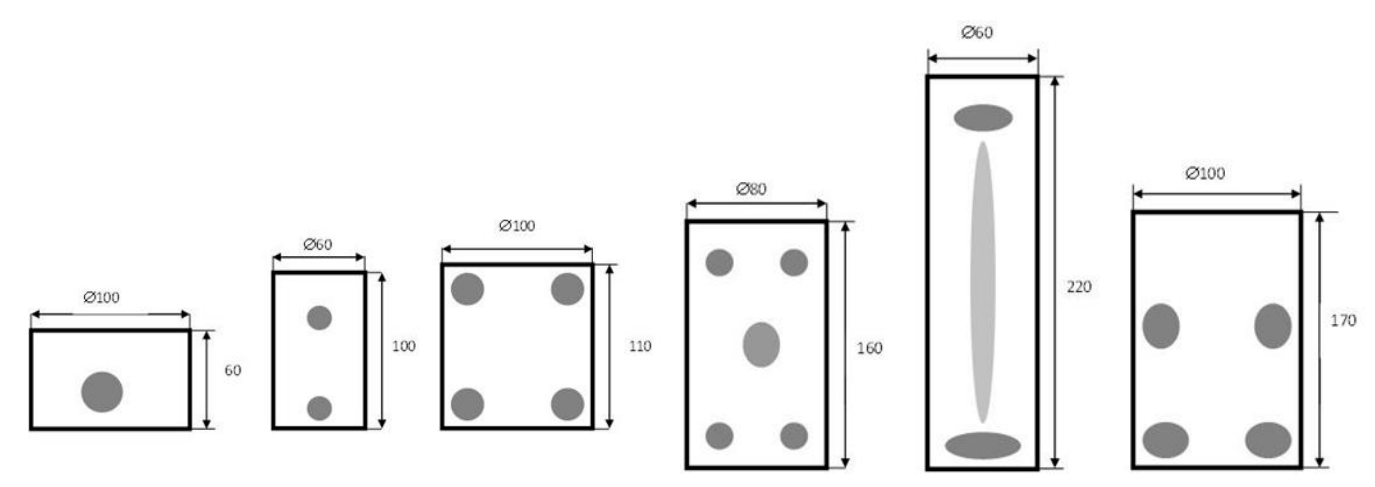

Figure 3. "Hot spots" in $\mathrm{Si}+\mathrm{C}$ synthesis. Sections of cylinder-shaped samples with the dimensions in millimetres. The shaded areas were detected in the plane perpendicular to the axis of the antenna and anti-antenna. The sample weights from left to right are $400 \mathrm{~g}, 250 \mathrm{~g}, 780 \mathrm{~g}, 780 \mathrm{~g}, 560 \mathrm{~g}, 1200 \mathrm{~g}$ [19].

\subsection{Typical Designs of Microwave Laboratory Devices}

The design of microwave reactors is a subject that aims to outstrip the limitations associated with the very nature of microwaves-their linear propagation, damping and absorption depending on the dielectric coefficient of the material crossing, and their propensity to form resonant structures. The reactor must be positioned in a metallic chamber, called the cavity, where the microwave energy is confined. There are several optimized cavity geometries, typically in the form of rectangular, cylindrical, or hexagonal chambers, or a combination of such shapes are commonly used. The microwave irradiation and its interaction with matter are characterized by processes such as absorption, transmission, and reflection.

The reactor vessel, if not composed of absorbing material, can be made of MW-transparent material, such as alumina, quartz, Pyre ${ }^{\circledR}$ glass, and so on. In this case, the microwave energy goes directly into the sample, crossing the container's walls without any losses. The geometry of the reactor vessel is crucial for dielectric heating, because the microwave energy is absorbed by the specimen volume until a certain depth, known as the "penetration depth" is achieved [18,20-22] (Table 1). Additionally, most of the organic materials, which the solvents include, behave similarly to water, in the sense that the dielectric loss will decrease with the increasing temperature.

Table 1. Penetration depths of the 2.45-GHz microwaves for some common solvents and materials [23].

\begin{tabular}{ccc}
\hline Material & Temperature in ${ }^{\circ} \mathbf{C}$ & Penetration Depth in $\mathbf{~ m ~}$ \\
\hline Methanol & 25 & $<1$ \\
Water (distilled) & 45 & 1.4 \\
Water (distilled) & 95 & 5.7 \\
Acetone & 25 & 7 \\
Toulene & 25 & $>40$ \\
Polytetrafluoroethylene (PTFE) & 25 & 9200 \\
Quartz glass & 25 & 16,000 \\
\hline
\end{tabular}


Under stop-flow conditions, the heating efficiency depends on the load diameter, while under continuous-flow conditions, the heating efficiency can increase linearly. Stop-flow conditions occur when the precursor is allowed to be stagnant in the microwave cavity, and the initial temperature is $25^{\circ} \mathrm{C}$. It is quite difficult for a batch reactor to achieve the desired temperature, and thus, it is permitted to cool down rapidly to get some other temperature spontaneously [24].

Another type of reactor configuration is typically used for brake linings for aircraft industry. This kind of configuration connects a system of tuners, like in a typical laboratory setting, by using a quartz glass capsule for a vacuum (Figure 4). Figure 5 shows typical optimized geometries of microwave modes with its description.

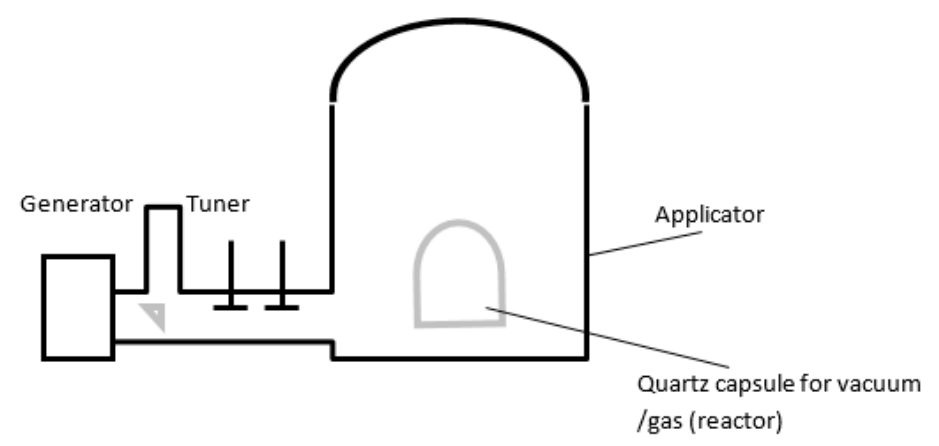

Figure 4. Scheme of experimental microwave system for high-temperature processes in a protective atmosphere. This system for obtaining brake linings for aircrafts is used in University of Birmingham [19].

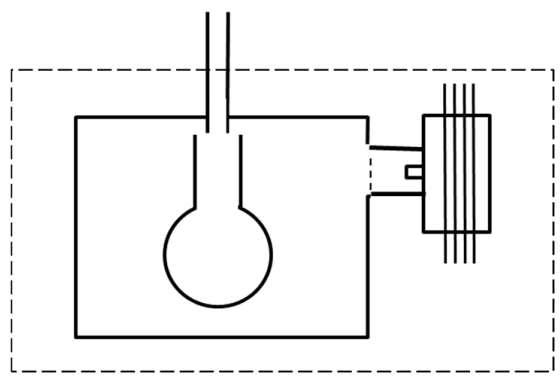

Use of a typical microwave oven for chemical experiments. A tube with a selected section protects against microwave leakage outside of the cavity and can be used as a measuring window or a distillate receiving channel.

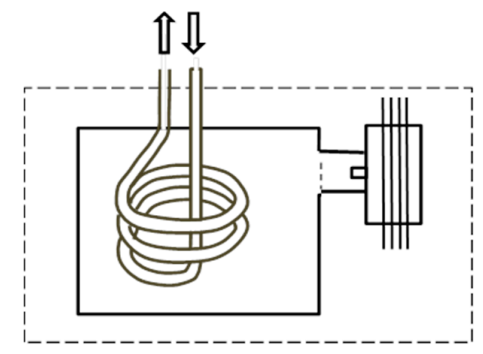

Another simple way to use a microwave oven for chemical experiments. A coil made of a pipe in microwave-transparent material.

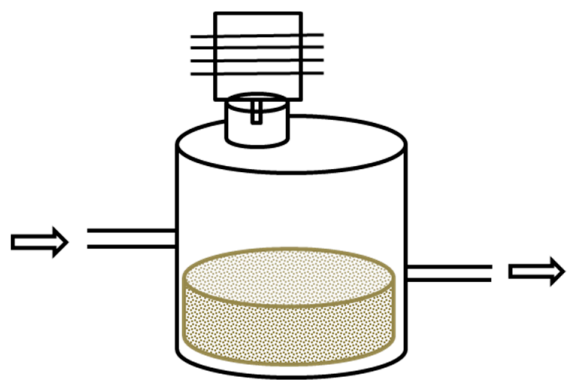

Simple container used for thermal processing in the flow mode. In this case, the metal applicator must be chemically resistant to the flowing chemicals. It is mostly used for polymers production (even $500 \mathrm{~L}$ ).

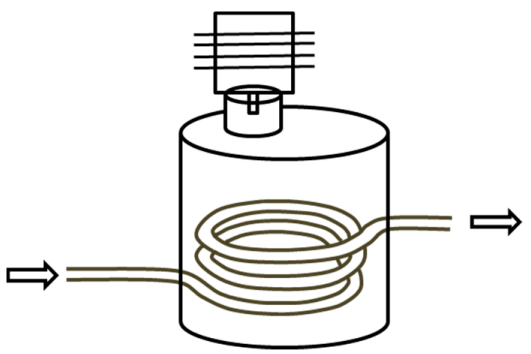

Another solution with a coil. In this case, very high and unique-to-microwave heating rates are accomplished.

Figure 5. Optimized geometries of the applicator shapes: rectangular and cylindrical for batch or continuous-flow modes (source: the IHPP PAS). 
In a typical chamber with a waveguide, small reaction containers can be placed on rotary tables, making full use of the magnetron power output. Such systems are commonly used in laboratories for the digestion or complete dissolution of samples intended for composition tests [25]. A major problem in their functioning might be the unequal temperature rise rate in different containers due to even slight inaccuracies in content batching.

\subsection{Process Parameters Control and Enhanced Pressure}

Usually, the power supply and all the components in the microwave devices manufactured today are assembled within a single structure together with the applicator (working chamber). In various configurations, the control may be performed by an external control module or a suitably programmed computer. If the system is not sealed for processing under enhanced pressure, temperature measurement is a sufficient monitoring and control tool. The items most commonly used for this purpose are thermocouples (ERTEC, others), PT100 sensors (SINEO, others), and optical or fiber-optic pyrometers (MILESTONE, CEM, SAIREM, Luxtron, etc.). The use of thermocouples or other metal detectors can give rise to serious concerns [26,27], because in a microwave field, it can generate measurement errors due to sparking [28] (see Figure 6). The fiber-optic thermocouples are unfortunately fragile. The cheapest way of measuring the temperature inside the chamber is evaluation by using an external thermocouple and known solid materials with well-known coefficients of thermal conduction. In our research, cases have occurred in which a damaged K-type shielded thermocouple generated a $4000{ }^{\circ} \mathrm{C}$ reading in the microwave field and then caused permanent damage to the temperature recorder (Figure 6).

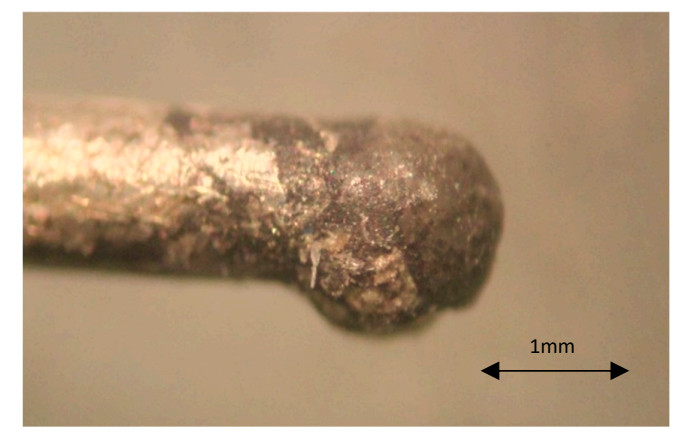

Figure 6. Magnified image of a damaged K-type thermocouple tip (source: IHPP PAS).

The suitability of microwaves for heating liquids in sealed reactors has been employed for various chemical processes [29]. The microwave digestion of samples has become a fundamental technique for the dissolution with acids of samples prepared for analysis in the liquid form. The sealed vessels' resistance to strong acids, availability of temperatures up to $300{ }^{\circ} \mathrm{C}$ (equilibrium pressure to $100 \mathrm{bar}$ ), and very high rates of microwave heating have enabled the shortening of the cycle of samples preparation for analytical tests, sometimes from many days to several minutes [25]. Similarly, in the organic synthesis reactions occurring under such conditions, a surprising increase is observed in the reaction yield and rate, often combined with a marked improvement in the product purity due to the specific catalytic effect [30]. Most important here is the ability to quickly obtain a high temperature as a result of microwave heating, as was described for nanopowder production in hydrothermal and solvothermal processes [29]. Basically, the high pressure autogenously produced in these conditions can play a positive role only if some substrates are in the gaseous form, although this is a rare case in laboratory practice. Therefore, solvents with high boiling points and high penetration depths can be used, such as glycol and glycerine. However, other factors should also be taken into account, such as the difficulty of dissolving many valuable reagents in some solvents or the difficulty of removing the remaining high-boiling point solvents from the products. Solvothermal synthesis with glycol as a solvent is expensive because of the costs of the solvents and the washing of the toxic solvents from the 
product of the synthesis (using a centrifuge with water washing). Therefore, water, and optionally, its solutions with different mineral or organic additives are the preferred reaction media, even if equipment fit for elevated pressures must be then used.

Nowadays, microwave applicators capable of withstanding pressures above 100 bar are rare, mainly due to the lack of suitable materials for the reactors. The most commonly used is polytetrafluoroethylene (PTFE), which provides high purity of the reaction medium but has a limited thermal stability (ca. $260{ }^{\circ} \mathrm{C}$, and less in an alkaline environment) [31]. Microwaves accelerate synthesis reactions. The use of microwave heating improves the homogeneity of the synthesis sludge, the narrow particle size distribution, the smaller size of the particles, and the conversion compared with other methods that do not use microwaves. Nanopowders made by microwave reactions have more active structures than those made by conventional methods.

\section{Measurements Problems}

As aforementioned, using measuring probes inside microwave applicators is difficult. Non-earthed metal components, among which thermocouples are included, can cause sparking and/or energy emission to the outside when subjected to strong polarization. Measuring instruments interoperable with sensors exposed to microwave irradiation are subjected to frequent damage as a result of the strong overvoltage generated by the significant electromagnetic power and very high strength of the generated field. This phenomenon is also associated with frequently observed interferences with other devices' operations caused by microwave devices and the spread of radiation directly into the environment, as well as via the supply chains. Every inherent characteristic of every solvent and all information about the solvent's interaction with the electromagnetic fields are important when the microwave protocols are performing. This information depends on the protocol for how to measure the temperature inside the microwave reactor. Strongly absorbing materials inside the reactor can confuse the IR sensor and show unreliable temperatures; this means that, for an IR sensor, the vessel/chamber material is not transparent for measurement. The better practice in that situation (i.e., ionic liquids inside the reactor vessel) is to use fiber-optic sensors, which are in contact with the reaction mixture [32,33]. Yet, on the other hand, strongly absorbing MW materials help to achieve better thermocouple measurements because of the better shielding of the temperature sensors. However, the need to accurately measure the reaction parameters forces equipment manufacturers to use measurement techniques in the microwave reactors. Milestone and Berghoff have measuring systems with pressure and thermocouple measurements. CEM and Anton Paar use IR sensors. Microwave power control and temperature control really have an immediate effect on the controlled reactions, thanks to which the size of the resulting nanoparticles can be controlled.

Figure 6 shows the tip of a K-type thermocouple in a $\varnothing 1$ Inconel $^{\circledR}$ sheath, damaged despite the sheathing's careful and proper grounding. It was damaged during the measurement of the temperature of pure water at about $250{ }^{\circ} \mathrm{C}$, and incorrect readings were noticeable. If a thermocouple of this type is used as a probe connected to the power supply control system, then similar damage going unnoticed may, in time, cause a dangerous failure. Additionally, thermocouples cannot be recommended for use in chemical reaction control, because the metals of which thermocouples are made raise the risk of product contamination.

In the currently offered microwave reactors, temperatures are only occasionally measured by thermocouples. Most commonly, thermocouples are placed outside of the microwave and chemicals impact zone (e.g., Magnum II by ERTEC), unless special field excitation means are used. A more useful system is temperature measurement with IR thermometers. Temperature measurement can be achieved by using an immersed temperature probe, such as a fiber-optic or gas balloon thermometer, or by using a device on the outer surface of the reaction vessel, such as a remote IR sensor. The use of any sensors inside the microwave reactors (e.g., pressure sensors) raises a huge risk that they will be damaged, and therefore, they are most commonly placed outside of the zone exposed to the electromagnetic field (see examples below), such as in MSS1 reactor, produced by ERTEC and IHPP PAS. 


\subsection{Optimal Performance and Configurations}

For specific heating applications in microwave reactions, it is commonly accepted to use an individual system of standardized reactor components, in which each variety of sets has a specific or dedicated function, so they can be arranged in any of several configurations, such as the typical system configuration used for heating a fluid column, with a single generator from a few watts to as much as several kilowatts.

Circulators and a dummy load are part of the two-port device isolator that allows microwaves to pass in a forward direction and prevents them from reversing. The main task is to protect the microwave generator and magnetron from reverse microwave power. The "dummy load" takes the reflected power, because circulators are not designed to absorb this kind of power.

The understanding of the necessary components, their meaning, and the possibility of optimization is the first strategy for buying or building a dedicated microwave reactor. Users have to make a decision regarding a few conditions: which type of sample they want to make and which temperature is demanded (solid or liquid sample, reaction temperature or cooling unit, and the type of used temperature devices). For every microwave, a user needs a generator compartment with a microwave generator (magnetron, klystron, solid-state semiconductor, or TWT) and a transmission compartment (waveguide, isolator, power monitor and tuners) [14].

As stated above, the configuration of the power delivery depends also on the waveguide components. The literature reports the following situations:

- No power delivery components - the magnetrons are mounted directly to the oven cavity (for big loss processes with known static loads);

- Impedance matching only - the magnetron is mounted to a short section of the waveguide (for high loss and static loads processes);

- No insulator-the typical laboratory set without a "dummy load" (it is a cheaper version than the "typical" one, but it can cause magnetron damage);

- Directional coupler before an insulator-the coupler is not set after the circulator like in typical heating system [34];

- Systems in which the microwave energy is supplied to the reactants by specially formed antennas.

\subsection{Materials for the Reactor}

The selection of appropriate materials for the reaction vessels and coils, in which the reactions occur, is a real problem. In order to avoid energy losses, the materials from which the reactor is made should not absorb microwaves (or absorb only a small amount), and at the same time, the materials must be able to resist high temperatures, thermal shocks, the aggressive impact of the chemical reaction medium, and sometimes high pressure. This issue is important even for cooking applications, and a number of special glasses and polymers suitable for healthy food heating have been developed. Unfortunately, for laboratories and chemical industries, they are of little practical use, because the chemical environment in the food industry is never as extreme as that in the laboratory [35].

In commercial microwave reactors, at least three materials have been found for reaction vessels, as well as pressure windows:

- High-quality polytetrafluoroethylene (PTFE), commercialized as Teflon ${ }^{\circledR}$, ALGOFLON $^{\circledR}$ HOSTAFLON $^{\circledR}$, FLUON $^{\circledR}$, CHEMLOY $^{\circledR}$, and so forth. This family of fluoroplastic resins has exceptional resistance to high temperatures, chemical reaction, corrosion, and stress-cracking. The mechanical toughness, and electrical and low-friction properties of Teflon ${ }^{\circledR}$ make it the preferred plastic for molding many different products and stock shapes, such as rods, tubes, and sheets. Products fabricated from PTFE are rated for continuous service at $260^{\circ} \mathrm{C}$ and provide exceptional low-temperature toughness, as well as unique low adhesion and flame resistance.

- Pure quartz glass, fused quartz, or fused silica are transparent materials consisting of silica in an amorphous (non-crystalline) form. They differ from traditional glasses, because no other 
oxides have been added during the melting process, thus leading to high working and melting temperatures. The optical and thermal properties of fused quartz are superior to those of other types of glass due to its purity; in particular, its most useful qualities are as follows: (i) It has a very low thermal expansion and an excellent thermal shock resistance; and (ii) it is very hard and chemically inert to most elements and compounds, including virtually all acids, regardless of concentration, except hydrofluoric acid, which is very reactive even in fairly low concentrations. Quartz glass possesses a marked refractoriness and can retain its shape, such as in crucibles, trays, and rollers, up to high temperatures $\left(1000-1500{ }^{\circ} \mathrm{C}\right)$. Unfortunately, it is fragile and easy to crack.

- Polyetheretherketone (PEEK) is a colorless organic thermoplastic polymer in the polyaryletherketone (PAEK) family with excellent mechanical and chemical resistance properties that are retained in high temperatures. Commercial PAEK products are as follows: AROTNE ${ }^{\circledR}, \mathrm{KARDEL}^{\circledR}, \mathrm{ZYEX}^{\circledR}$, and PEEK-VICTREX ${ }^{\circledR}$. The processing conditions used to mold PEEK can influence its mechanical properties (Young's modulus: 3.6 GPa; tensile strength: 90-100 MPa). PEEK has a useful operating temperature up to $250{ }^{\circ} \mathrm{C}$, and it is highly resistant to attack in both organic and aqueous environments. It can withstand attacks by halogens and strong Brønsted and Lewis acids, as well as some halogenated compounds and aliphatic hydrocarbons, at high temperatures. It is soluble in concentrated sulfuric acid at room temperature with a slow kinetic rate. For these reasons, PEEK is often used with an internal PTFE coating.

When these materials are not available, a good substitute could be sodium borosilicate glass, commercialized as Pyrex ${ }^{\circledR}$, Duran ${ }^{\circledR}$, and so on. Used for chemical glassware for many years, borosilicate glasses have fairly low coefficients of thermal expansion [36], making them more dimensionally stable and thus, less vulnerable to cracking from thermal shock.

\subsection{Microwave Reactors Applied to Chemical Processes}

\subsubsection{Microwave Digestors for Sample Mineralization}

The main purpose of the digestion process is the complete dissolution of the samples for subsequent analyses. Over the years, microwave digestors have also been successfully used for organic and inorganic syntheses, which hundreds of scientific articles have reported. The main types of microwave mineralizer designs are shown schematically in Figure 7, where multi-cup and single-cup setups are reported. As a rule, a multi-cup mineralizer has a non-pressurized microwave cavity, because high pressure is achieved in sealed vessels placed on a rotary tray. Temperature and pressure are measured in individual vessels (Milestone). However, the known control problems with devices of this type are the observable differences in the operating temperatures and pressures, which can be significant, even for small differences in the volumes and composition of the digested substance. Most often, this does not prevent good preparation of the samples digested for analysis, but it is a serious obstacle when the device is used to perform a controlled synthesis reaction. Such devices most commonly deliver the energy through a waveguide from one or more magnetrons. Exceeding the critical pressure in any of the vessels usually leads to the blowing up of the device's door (or cover) and is the most common cause of major system failures. Mineralizers of this type are offered by the main producers, such as CEM, MILESTONE, and others. Microwave digestors are especially needed for chemical characterization and analysis of nanometric materials (e.g., ICP-MS or ICP-OES methods). 


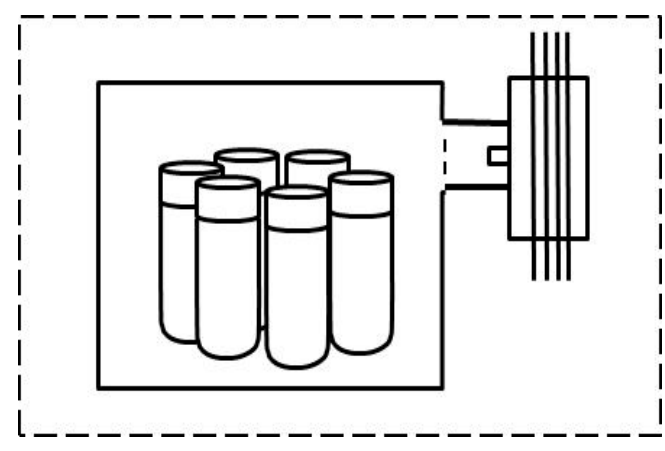

(a)

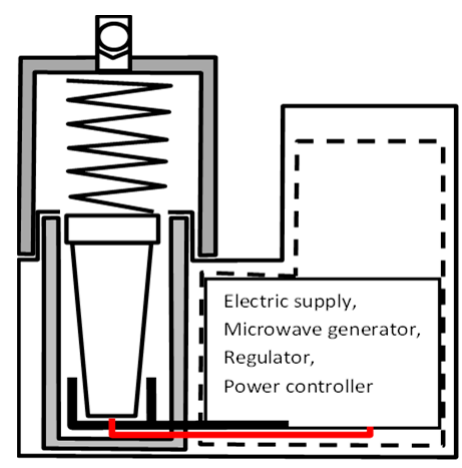

(b)

Figure 7. Microwave digestor geometries: (a) multi-cup mineralizer (b) single-cup ERTEC (source: the IHPP PAS).

\subsubsection{Inorganic Synthesis of Nanomaterials}

Non-organic chemicals (e.g., metals, oxides, and other metallic or non-metallic compounds) are produced in a microwave reactor in a way that is essentially similar to the known hydrothermal and solvothermal methods. The raw materials are the same, and the reactant concentrations and other reaction conditions are similar. Compared with the conventional techniques, the obvious advantages of microwave heating are that the internal heating is more uniform, the reaction completes right at a selected time, and heating rates are superior $[1,37,38]$. The issues of what equipment a reactor should have for the synthesis of nanomaterials and what properties such a device should have must also be considered. We believe that the reactor for the chemical synthesis of nanomaterials should have a greater power capacity in the generator (more than $2 \mathrm{~kW}$ ), be made of chemically inert elements, and be easy to change and clean in case it needs to synthesize different materials. An important element is the measurement of pressure and temperature and the ability to easily repeat the results and parameters of a reaction. To make a series of nanopowders, the reaction should be stopped immediately at specific times during the reaction. This problem can be solved by using an MSS2 reactor (stop-flow or batch-type) in IHPP PAS in Warsaw [39].

As a result, such a process can be designed, which produces nanometric materials that are difficult to procure by other methods [40,41]. An example is zinc oxide, which is usually obtained in the form of a powder with an average grain diameter of above $100 \mathrm{~nm}$ [42], while as a result of a solvothermal-microwave process, the average grain diameter can be even less than $60 \mathrm{~nm}$ [43]. A similar $\mathrm{ZnO}$ synthesis method independently developed at IHPP PAS, involving an MSS2 reactor [44] and zinc acetate as a raw material in an ethylene glycol environment, allows for the very precise planning of the $\mathrm{ZnO}$ nanoparticles size in the range of 15-120 nm (specific surface area by the BET method (SSA BET) 74-9 m²/g) [45-47]. In solvothermal synthesis, it is possible to obtain many NPs (nanoparticles) doped by other elements and displaying different morphologies and different shapes. In Figure 8 it is easy to notice many type of shapes of $\mathrm{ZnO}$ obtained in solvothermal method [48,49], every shape Figure $8 \mathrm{a}-\mathrm{f}$, depends of changes protocol during the solvothermal synthesis.In IHPP PAS, $\mathrm{ZnO}$ doped with $\mathrm{Mn}, \mathrm{Co}, \mathrm{Ni}, \mathrm{Cr}$, or $\mathrm{Ag}$ was obtained [49-54]. Doped elements are visually easy to notice as is their quantity (Figure 9) [48,49], 


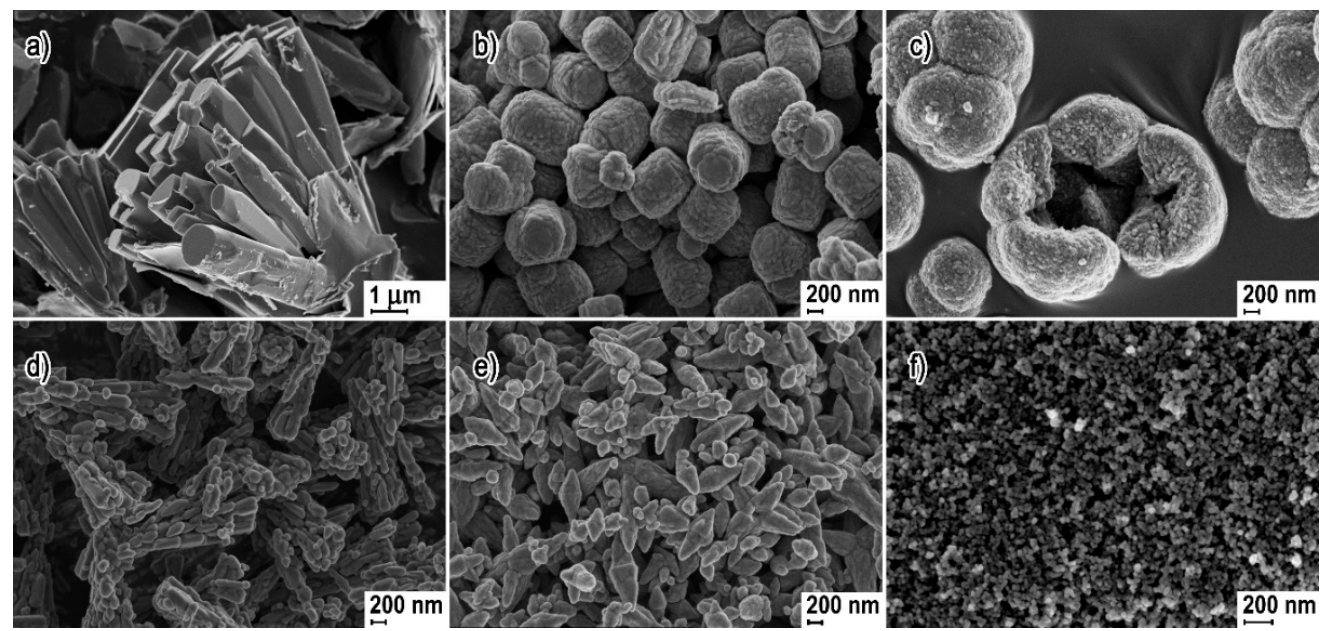

Figure 8. SEM of $\mathrm{ZnO}$ synthesized in IHPP PAS by a microwave solvothermal method: (a) ZnO rods, (b) $\mathrm{ZnO}$ barrels, (c) $\mathrm{ZnO}$ flowers, (d) ZnO sticks, (e) $\mathrm{ZnO}$ irregular particles, (f) ZnO spherical NPs.

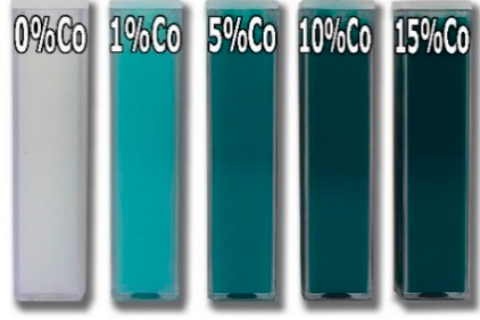

(a)

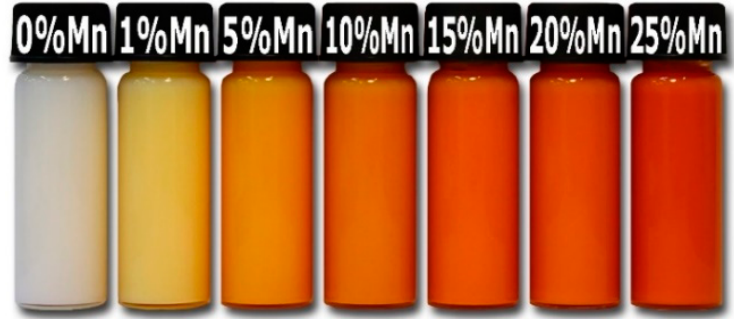

(b)

Figure 9. Synthesized $\mathrm{ZnO}$ with doped elements (a) Co (b) Mn [48,49].

Using glycerol as the reaction medium, a metallic copper powder was produced from copper hydroxide (the phenomenon of melting copper particles into large balls, which led to ERTEC reactor failure, was observed). Furthermore, this research proved that microwave solvothermal synthesis enables us to control the size of the $\mathrm{ZnO} N P s$ aggregates within the range from $60 \mathrm{~nm}$ to $120 \mathrm{~nm}$, at the same time preserving the constant size of single $\mathrm{ZnO} N P s(\approx 27 \mathrm{~nm})$ (Figure 8) [55].

The hydrothermal technique provides an excellent potential for processing many materials from crystals to nanoparticles (e.g., $\mathrm{SiO}_{2}, \mathrm{TiO}_{2}, \mathrm{Al}_{2} \mathrm{O}_{3}, \mathrm{SnO}_{2}, \mathrm{HfO}_{2}, \mathrm{Fe}_{3} \mathrm{O}_{4}, \mathrm{CdTe}$ and others for which it is also possible to make doped powders) [56-63]. The MW synthesis produces more consistent samples than the sol-gel method. The results from helium pycnometer measurements regarding $\mathrm{Al}_{2} \mathrm{O}_{3}-\mathrm{ZrO}_{2}$ composites show that the sol-gel nanopowders have lower densities than those nanopowders synthesised by microwaves $[62,63]$. Microwave hydrothermal synthesis also results in a fine distribution of intermixed highly crystalline nanoparticles of boehmite and zirconia and produces a narrow size distribution [64]. The microwave hydrothermal synthesis delivers energy directly to the substance without thermal-conductivity-related constraints. Today, the hydrothermal method is used for processing particles to form nanoparticles with a controlled grain size and morphology. In the IHPP PAS, we obtain hydroxyapatite (GoHAP) with a size as small as $8 \mathrm{~nm}[65,66]$. At this laboratory, the microwave reactors produce iron oxides with a grain size of $20 \mathrm{~nm}$, zirconium dioxide ca. $10 \mathrm{~nm}$ [67], zirconium dioxide_doped $\mathrm{Eu}, \mathrm{Nd}, \mathrm{Gd}$, or $\mathrm{Tb}$ [67-69], and $\mathrm{Ca}_{5}\left(\mathrm{PO}_{4}\right)_{3} \mathrm{OH}$, GoHAP with an average grain diameter of 8-40 $\mathrm{nm}$ controlled by the time and temperature of reaction [65,66]. In IHPP PAS, it is possible to obtain six types of GoHAP with a narrow size distribution and different characteristics of nanostructures (Figure 10). Figure 10 shows six different types of hydroxyapatite obtained by precipitating and hydrothermal method. 

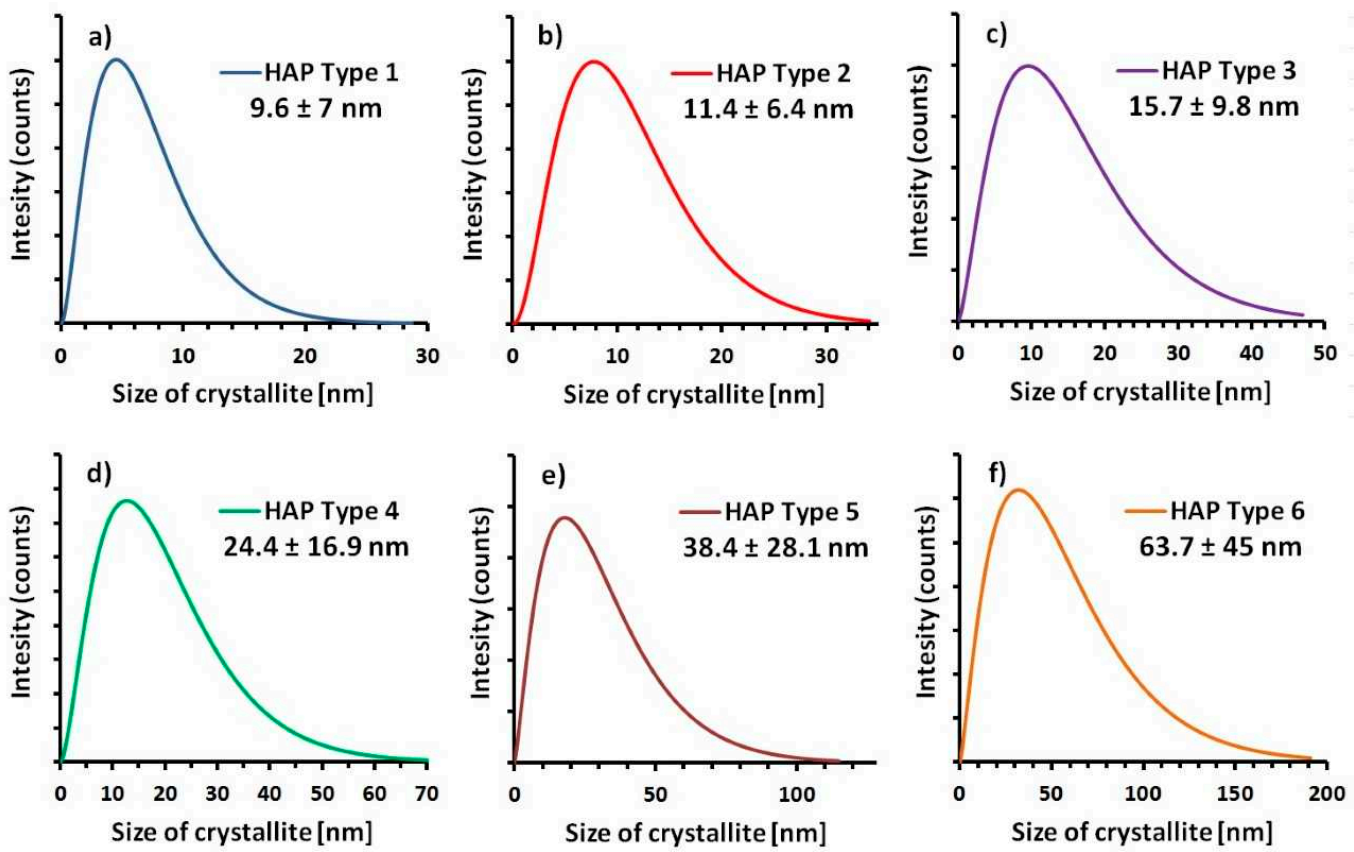

Figure 10. Size distribution of six types of hydroxyapatite (now called GoHAP) synthesized by the microwave hydrothermal method in an MSS2 reactor $(\mathbf{a}-\mathbf{f})$ shows different types of hydroxyapatite synthesized in IHPP PAS [66].

Hydrothermal technology, like solvothermal methods, has a great potential to be the leader in processing a wide variety of advanced materials. It is called the "green" chemistry method in that it facilitates wasteless processing without contributing to global warming or air pollution [70-74]. "Green" chemistry is about the design of chemical products and processes that can reduce or eliminate the use or generation of hazardous and dangerous substances. Water is the most "green" solvent because of its non-toxicity, and it is also inexpensive and is easily isolated from the product (GoHAP). Some metallic particles may be obtained in microwave reactors (e.g., $\mathrm{Cu}, \mathrm{Ag}$, $\mathrm{Au}$ ) provided that they do not agglomerate [61]. It should also be taken into consideration that nanopowders can strongly absorb MW in reactions such that more than substrates may form.

Our approach to syntheses at IHPP PAS is very factual. We want to have repeatable results, with the ability to control the changes therein. Synthesis should be clean and chemically inert without introducing other contaminants from the air and the materials of construction of the reactor. As much as possible, the amount of precursor should be used conservatively during synthesis without losing the quality of the suspension produced. During the synthesis, as much as possible should be known about the pressure and temperature prevailing therein in order to eliminate inappropriate temperature jumps and to optimize the process and the results of the reaction, such as narrow size distribution.

\subsubsection{Examples of Applications for Organic Synthesis}

The reference literature on the use of microwave techniques in organic chemistry is very rich $[35,75]$. The courses of many organic reactions in microwave reactors differ from previously known patterns, and numerous examples are cited [76]. Many researchers relate the observed phenomena to the formation of temperature gradients [77]. Microwave-induced synthesis has been applied in the chemistry of polymers [78,79] and pharmaceuticals [80], and an accurate description of their industrial application is very hard to find. Much wider use of microwaves has occurred in the extractions of drugs or foods from many plant materials [81]. A particularly important aspect of microwave technology is the potential to achieve the very delicate heating of raw materials, with the overheating risk as low as possible, in low $\left(0-20^{\circ} \mathrm{C}\right)$ temperatures, often in parallel with enhanced pressure. 
Currently, the offerings of most leading manufacturers of microwave reactors are also targeted at the synthesis of pharmaceuticals; this application segment is addressed by Milestone, Lambda, Sineo, Anton Paar, etc. The use of specialized automated microwave reactors has led to a remarkable development of new pharmacological substances due to the acceleration of a series of tests carried out over weeks instead of over years, as is the case using the classic techniques [82].

Recently, there has been significant interest in applying microwave reactors to the processing of various kinds of raw materials, as well as waste, into fuel [83]. As microwaves penetrate the liquids or suspensions therein, heating them rapidly, it is relatively easy to design devices with large sizes and high outputs. We can divide the microwave chemistry into the four categories: "green" chemistry, operating mode, chemical reactions, and specific heating. The major applications of these benefits are organic chemistry, biochemistry, and catalysis.

Microwave heating efficiency can be enhanced by combination with the synergy impacts of other unconventional chemical reaction stimulation techniques, such as ultraviolet irradiation or ultrasonic stimulation [84]. The relevance of the microwave and ultrasound combination has been shown in the processes of extraction, the production of biofuels, other organic syntheses, and the production of oxide and metallic nanopowders. Nowadays, many researches endeavor to obtain and use elevated pressure, to make shorter and more effective syntheses or sintering. Synthesis at 50 bar is a few times quicker than synthesis of nanoparticles at a few bar inside the chamber/vessel. In MSS2, IHPP PAS can autogenously obtain $10 \mathrm{bar}$ and ca. $180^{\circ} \mathrm{C}$ in $1 \mathrm{~min} 45 \mathrm{~s}$ and 50 bar in $4 \mathrm{~min}$, using a $3000 \mathrm{~W}$ power output. Of course, the condition for effective control of these reactions, as in the case of the production of nanopowders, is the most accurate measurement of the temperature in the reactor. The pressure placed by users and laboratories on accurate temperature measurement is constantly increasing.

\section{Overview of Microwave Reactors}

\subsection{Main Producers of Microwave Devices with Parameter Control}

Usually, better process control is required for chemical syntheses than for mineralizers, although some devices, such as MAGNUM II by ERTEC, perfectly fulfil several functions (mineralizer and reactor in one). In particular, very accurate temperature control and regulation are desirable. Reaction vessels sizes are tailored to the needs of the user, although they are also subjected to basic limitations related to the applicable regulations with which their manufacturers must comply, beginning at the stage of design assumptions. For nanopowder synthesis, devices, such as ERTEC Magnum II, CEM VOYAGER and Milestone/UltraWAVE/SynthWAVE, could be used. Table 2 presents some interesting microwave reactors for the laboratory scale.

Table 2. Main producers of microwaves devices.

\begin{tabular}{|c|c|}
\hline \multicolumn{2}{|c|}{ MICROWAVE DEVICES AT THE LABORATORY SCALE } \\
\hline EXAMPLE PICTURE & DESCRIPTION \\
\hline www.berghof-instruments.com & $\begin{array}{l}\text { Berghof Speedwave Xpert, with a toploader design, is easy to } \\
\text { handle. The digestion vessels are inserted into a rotor from } \\
\text { above and taken out again. The power output of the magnetron } \\
\text { is } 2000 \mathrm{~W} \text {. }\end{array}$ \\
\hline www.berghof-instruments.com & $\begin{array}{l}\text { Berghof Speedwave Entry is optimized for the digestion of } \\
\text { sample materials. It is easy and quick to start. The software } \\
\text { offers a range of applications to the routine analysis. } \\
\text { The magnetron power output is } 1000 \mathrm{~W} \text {. }\end{array}$ \\
\hline
\end{tabular}


Table 2. Cont.

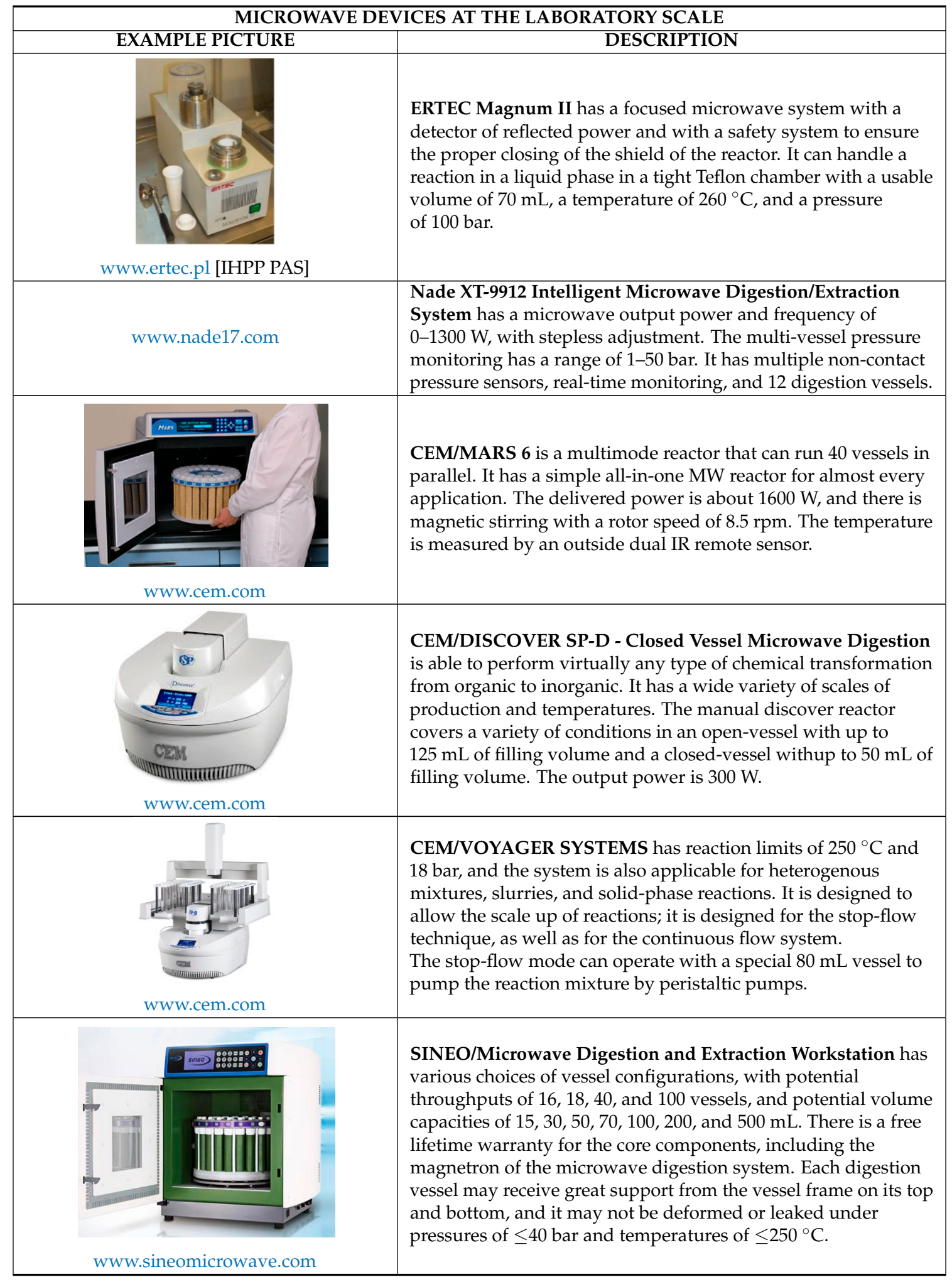


Table 2. Cont.

\begin{tabular}{|c|c|}
\hline \multicolumn{2}{|c|}{ MICROWAVE DEVICES AT THE LABORATORY SCALE } \\
\hline EXAMPLE PICTURE & DESCRIPTION \\
\hline & $\begin{array}{l}\text { SINEO MDS-15 High-throughput Microwave Sample } \\
\text { Preparation Workstation has a } 500 \mathrm{~mL} \text { ultra-large digestion } \\
\text { vessel that meets the special requirements for the digestion of } \\
\text { samples of up to } 10 \mathrm{~g} \text {. The drying rotor aides in the drying } \\
\text { process of samples. Sineo's patented safety bolt design } \\
\text { eliminates the need for explosion-proof membranes and other } \\
\text { costly consumables. }\end{array}$ \\
\hline www.milestonesci & $\begin{array}{l}\text { Milestone/UltraWAVE/SynthWAVE can achieve a scale up for } \\
\text { chemical reactions from grams to the kilogram range. It takes } \\
\text { single and multiple reactions at temperatures close to } 300{ }^{\circ} \mathrm{C} \text { and } \\
\text { pressures up to } 199 \text { bar. Reactions can be carried out directly in } \\
\text { the } 1 \mathrm{~L} \text { PTFE vessel or in multiple vials. Its vials are available in } \\
\text { glass, quartz, or PTFE, fitted with loose PTFE caps to ensure } \\
\text { pressure equalization. Its available rack configurations include } 4 \text {, } \\
5,15 \text {, and } 22 \text { positions. }\end{array}$ \\
\hline & $\begin{array}{l}\text { Anton Paar Masterwave BTR, with productivity increased up } \\
\text { to kilogram amounts per day, it has } 1700 \mathrm{~W} \text { installed microwave } \\
\text { power. It has an integrated mechanical stirrer with } \\
\text { software-guided stirring and can accommodate reaction } \\
\text { conditions up to } 250^{\circ} \mathrm{C} \text { and } 30 \text { bar. It has constantly circulating } \\
\text { microwave-transparent cooling liquid. It offers } \\
\text { industry-validated productivity. }\end{array}$ \\
\hline & $\begin{array}{l}\text { Anton Paar Monowave } 400 \text { and Monowave } 200 \text { are high } \\
\text { performance MW reactors designed for small-scale synthesis } \\
\text { applications in research and development laboratories. } \\
\text { The autosampler option allows for unattended sequential } \\
\text { processing of } 24 \text { experiments. }\end{array}$ \\
\hline wwr & $\begin{array}{l}\text { Sairem the MiniFlow 200SS is an easy-to-use } \\
\text { microwave-assisted reactor, specifically designed for chemistry } \\
\text { and pharmaceutical applications that provides the option to } \\
\text { work with small quantities of sample and equally, to be used as a } \\
\text { teaching device that allows the user to learn and understand the } \\
\text { principles of microwaves. The system can be easily configured to } \\
\text { perform different applications, including reactions in the liquid } \\
\text { phase, solid phase, and gas phase in homogeneous and } \\
\text { heterogeneous mixtures. }\end{array}$ \\
\hline & $\begin{array}{l}\text { Chemspeed SWAVE is a medium microwave synthesizer } \\
\text { station from Chemspeed that incorporates a Biotage Initiador } \\
\text { with the features necessary to enable a fully automated synthesis } \\
\text { workflow form. It allows for the addition of reagents under an } \\
\text { inert atmosphere, solid weighing, direct dispensing, } \\
\text { and liquid handling. }\end{array}$ \\
\hline www.enbiogroup.pl & $\begin{array}{l}\text { Autoclaws ENBIOJET is a popular, simple sterilizer that uses } \\
\text { traditional transformer generators, magnetrons, and waveguides. } \\
\text { The specially designed shape of the applicator chamber allows } \\
\text { for convenient use of typical laboratory vessels of up to } 500 \mathrm{~mL} \\
\text { capacity. As much as } 0.5 \mathrm{~L} \text { of water in a glass laboratory flask } \\
\text { with a diameter of up to } 120 \mathrm{~mm} \text { can be effectively heated to } \\
135^{\circ} \mathrm{C} \text { in } 1.5 \text { min using two microwave sources with a pressure } \\
\text { enhanced to } 3.5 \text { bar. }\end{array}$ \\
\hline
\end{tabular}




\subsection{Reactors Designed for Scale-Up}

Laboratory-scale microwave reactors are capable of producing up to tens of grams of materials, where pharmaceutical compounds are mainly concerned. In most cases, in order to implement industrial production, this scale has to be expanded more than several times. Many companies have developed reactor models that are good for both: experiments on the laboratory scale and the subsequent scale-up. Many researchers are constructing their own customized microwave chemical reactors. The primary example is the Institute of High Pressure Physics PAS with the cooperation of ERTEC, and the Institute for Sustainable Technologies National Research Institute, which is building and developing their own microwave reactors for the chemical nanopowder syntheses of $\mathrm{ZnO}, \mathrm{ZrO}_{2}$ and GoHAP, for instance. For bigger scale-up in microwave-assisted organic synthesis (MAOS), the most important technology is the continuous-flow method in an open- and close-loop mode. Microwave irradiation fastens the emulsion polymerization by 70 times compared with conventional heating [84]. The microwave-assisted synthesis of polymers results in narrower molecular weight distributions. Nowadays, more and more ceramic/solid sintering is made in microwave processing (for example, a gyrotrons generator uses $28 \mathrm{GHz}$ for laboratory big-scale sintering). Table 3 shows the variety of scale up microwave reactors in stock.

Table 3. Main producers of large-scale microwave applicators.

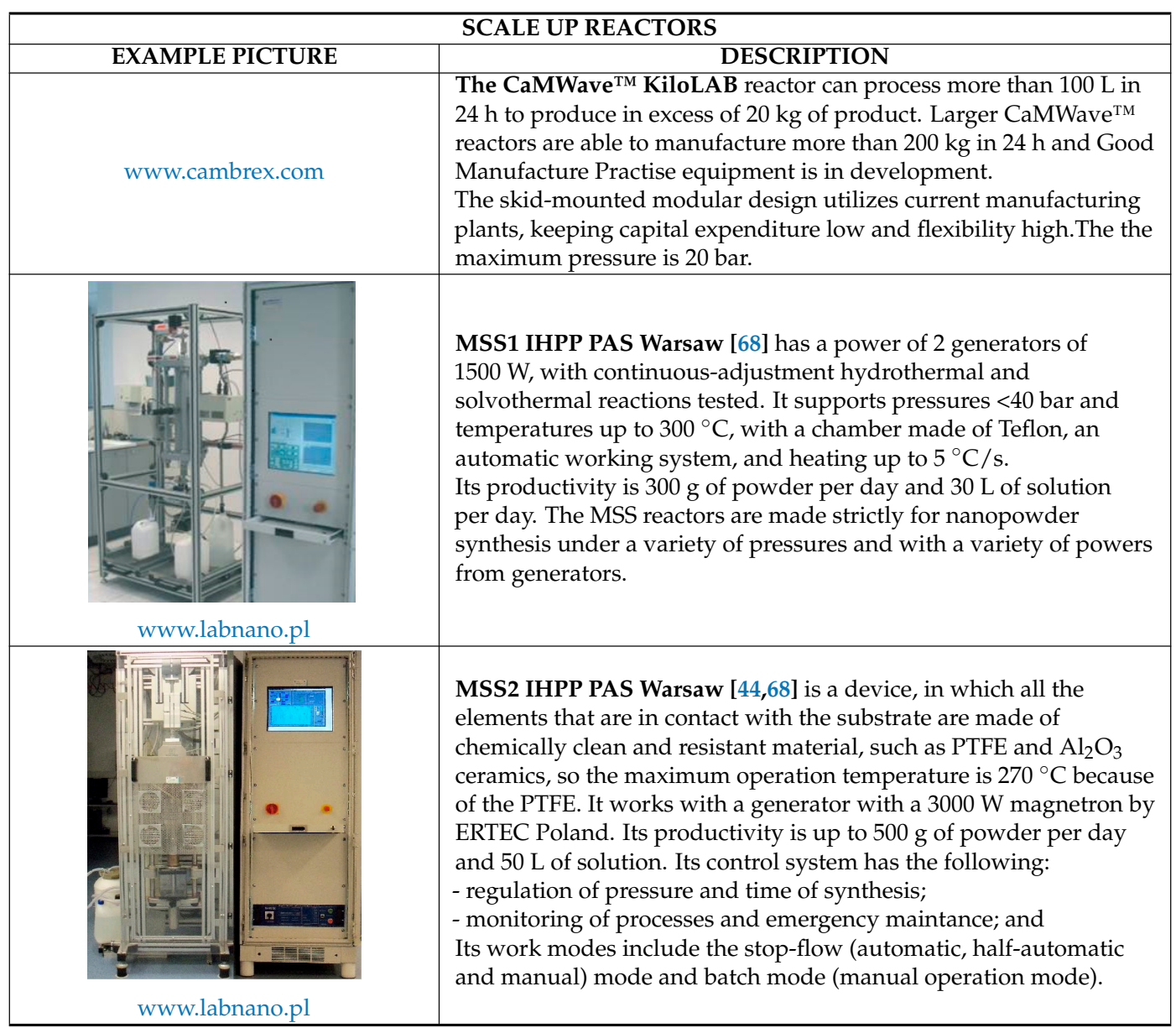


Table 3. Cont.

\begin{tabular}{|c|c|}
\hline \multicolumn{2}{|r|}{ SCALE UP REACTORS } \\
\hline EXAMPLE PICTURE & DESCRIPTION \\
\hline$\frac{11}{\xi_{0}^{\text {4homonon }}}$ & $\begin{array}{l}\text { The LABOTRON improves considerably the performance of } \\
\text { microwave-assisted chemistry due to the following: adjustable } \\
\text { power from a few watts to many kilowatts; optimized geometry of } \\
\text { the INTLI to achieve high-power densities inside the reactor up to } \\
10 \mathrm{~kW} / \mathrm{L} \text {; direct reading of the forward and reflected power values } \\
\text { to enable the correct calculation of the energy absorbed by the } \\
\text { sample; and efficient mechanical stirring with adjustable speeds. } \\
\text { The reactors are adapted for homogeneous and heterogeneous } \\
\text { chemistry in liquid and solid phases. It has quick connections for } \\
\text { increased flexibility and rapid cleaning and maintenance. }\end{array}$ \\
\hline www.sairem.com & \\
\hline
\end{tabular}

In many applications, the flexibility of the device is one of the most important advantages. For example, the MSS2 reactor is designed for automatic operation in the stop-flow mode, and we have adapted it to work in batch mode with the appropriate containers for one-time or reusable use, because we have estimated that it practically facilitates the execution of many experimental works. Changing the reactor's arrangement takes less than $2 \mathrm{~h}$. The MSS1 and MSS2 reactors are especially made for nanopowder synthesis, similar to old Lambda systems and the Sineo Selon-1000 reactor.

\subsection{Hybrid Reactors}

A small number of microwave applicator producers are now offering dielectric heating combined with ultraviolet or ultrasound devices [85]. Starting with a simple and original microwave photochemical reactor consisting of an electrodeless discharge lamp placed into the reaction vessel in a modified domestic microwave oven, the technology has evolved to facilitate the combination of photoactivated radical environments with high heating rates [86]. The microwave heating efficiency can be enhanced by its combination with the concurrent impacts of other unconventional chemical reaction stimulation techniques, such as UV irradiation or ultrasonic stimulation. The combination of the microwave and ultrasounds has been shown in the processes of extraction, production of biofuels, and production of oxide and metallic nanopowders, they are called hybrid reactors (Table 4).

Table 4. Main producers of combined microwave applicators.

\begin{tabular}{|c|c|}
\hline \multicolumn{2}{|r|}{ HYBRID REACTORS } \\
\hline EXAMPLE PICTURE & DESCRIPTION \\
\hline & $\begin{array}{l}\text { UWave-2000 Multifunctional Microwave Chemistry Reaction } \\
\text { Workstation integrates the atmospheric pressure and } \\
\text { pressurized reaction, microwave, ultrasonic wave and ultraviolet } \\
\text { irradiation, and other functions, giving full flexiblility to the user. } \\
\text { The microwave automatic frequency conversion control, dual } \\
\text { temperature control technology, and piezoelectric crystal } \\
\text { pressure can ensure the accurate record and representation of } \\
\text { each reaction. The microwave source is } 1000 \mathrm{~W} \text { and the } \\
\text { adjustable scope of the ultrasound power is } 0-800 \mathrm{~W} \text {. }\end{array}$ \\
\hline 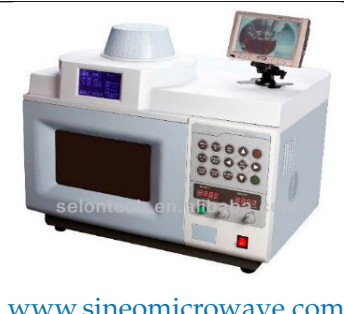 & $\begin{array}{l}\text { UWave-1000 Sineomicrowave has the following features: } \\
\text { automatic variation range of microwave power: } 0-1000 \mathrm{~W} \text {; } \\
\text { ultrasonic working frequency: } 26-28 \mathrm{KHz} \text {; power regulation } \\
\text { range: } 0-800 \mathrm{~W} \text {; ultraviolet irradiation light source wavelength: } \\
365 \mathrm{~nm} \text {; power: } 300 \mathrm{~W} \text {; temperature control: from room } \\
\text { temperature to } 300^{\circ} \mathrm{C} \text {; and reaction container volume: } \\
50-1000 \mathrm{~mL}(10 \mathrm{~mL} \text { and } 20 \mathrm{~mL} \text { are optional). The reaction } \\
\text { container material is quartz glass, and the range of the operating } \\
\text { time is from } 1 \mathrm{~s} \text { to } 6000 \mathrm{~min} \text {. }\end{array}$ \\
\hline
\end{tabular}


Table 4. Cont.

\begin{tabular}{|l|l|}
\hline & \multicolumn{2}{|c|}{ HYBRID REACTORS } \\
\hline EXAMPLE PICTURE & $\begin{array}{l}\text { DESIPTION } \\
\text { Milestone ATC-FO } 300 \text { MultiSYNTH Single and Multi-Mode } \\
\text { Microwave Synthesis System is a so-called hybrid device. } \\
\text { It has an ability to merge into a single-mode reactor, as well as a } \\
\text { multimode reactor. A single magnetron with a homogenous } \\
\text { microwave distribution in the cavity has a } 800 \text { W output power } \\
\text { for the multimode configuration. For the single mode, the output } \\
\text { power is only } 400 \text { W. It has an immersed fiber-optic probe and } \\
\text { indirect pressure control with an outside IR remote sensor. For } \\
\text { the single-mode format, } 2.5 \text { and } 10 \text { mL glass virals are provided } \\
\text { with a temperature limit of } 250{ }^{\circ} \mathrm{C} \text { and a pressure limit of } 20 \text { bar. }\end{array}$ \\
\hline
\end{tabular}

\subsection{High-Temperature Microwave Reactors (Sintering Furnaces)}

Microwaves and microwave devices can easily and quickly reach $1000{ }^{\circ} \mathrm{C}$ to dry ceramic powders. Sintering equipment with klystron or gyrotron has been developed mostly for this purpose. The most important issue is that, inside the microwave device, solid or powder cannot be stirred, so the temperature distribution plays a key role. Thus, a multimode applicator should be used. The microwave devices can be used to process ceramics and achieve rapid sintering of inorganic materials $[87,88]$. Microwave sintering produces a finer grain size and different shapes from the conventional process [14] (Table 5).

Table 5. Main producers of sintering microwave equipment.

\begin{tabular}{|c|c|}
\hline \multicolumn{2}{|c|}{ HIGH-TEMPERATURE MICROWAVE REACTORS } \\
\hline EXAMPLE PICTURE & DESCRIPTION \\
\hline www.ce & $\begin{array}{l}\text { CEM Phoenix } x^{\mathrm{TM}} \text { Microwave Muffle Furnace has a speed that is up } \\
\text { to } 10 \text { times faster than the conventional muffle furnaces and a } \\
\text { capacity of up to } 15 \text { samples at one time. } \\
\text { The high-temperature furnaces reach } 1200^{\circ} \mathrm{C} \text { and can process up to } \\
\text { eight } 25 \mathrm{~mL} \text { crucibles. For laboratories needing greater throughput, } \\
\text { the high-capacity furnaces reach up to } 1000^{\circ} \mathrm{C} \text { and hold up to fifteen } \\
25 \mathrm{~mL} \text { crucibles. It can process any crucible that can be used in a } \\
\text { conventional muffle furnace (including platinum). }\end{array}$ \\
\hline . & $\begin{array}{l}\text { FlexiWAVE is a high-temperature muffle reactor with an extremely } \\
\text { fast heating rate }\left(5 \mathrm{~min} \text { to } 800^{\circ} \mathrm{C} \text { and } 10 \mathrm{~min} \text { to } 1000^{\circ} \mathrm{C}\right) \text {. Nowadays, } \\
\text { it is a first } \mathrm{MW} \text { reactor for chemical synthesis able to work at } 1200 \\
{ }^{\circ} \mathrm{C} \text {. }\end{array}$ \\
\hline www.weisstechnik.be & $\begin{array}{l}\text { Vötsch Industrietechnik was introduced at JEC Europe } 2013 . \\
\text { As a very energy efficient method for curing fiber composite } \\
\text { components in microwave technology, the modular microwave } \\
\text { system can accomodate large components. The patented hexagonal } \\
\text { cavity shape for a uniform field distribution is useful for making } \\
\text { high-quality products. Compared with convectional heating } \\
\text { methods, this device saves up to } 70 \% \text { energy and has a working } \\
\text { chamber volume between } 750 \mathrm{~L} \text { and } 7000 \mathrm{~L} \text {. }\end{array}$ \\
\hline
\end{tabular}




\section{Future Developments in Microwave Chemistry}

- The development of microwave technology has allowed for its wider use in further areas of research and production. We believe that we can expect particularly intensive progress in the field of new materials, which is useful for increasing the operational parameters of devices and further disseminating of effective methods for the synthesis of valuable products (e.g., pharmaceuticals, nanopowders).

- The development of materials, such as semiconductor generators for replacing magnetrons and TWT for power supplies in microwave reactors, will continue to increase efficiency. Unfortunately, semiconductor supplies are currently still too expensive for use in all devices. In the next few years, the hope is that the price will fall dramatically, and it will be possible to use semiconductors (very small supply) for domestic cooking purposes to obtain shorter heating times than those that are currently available.

- The increased use of Internet/Bluetooth connections will have positive benefits on cooking household and laboratory experiments. This will allow users to avoid having to keep an "eye" on everything, because dices could be started and initialized by using an Internet/Bluetooth connection. The laboratory data can be sent by the cloud, and some calculations can be done for the user while the reaction is running.

- Sensors for properly using power and managing the time of cooking/chemical reactions will be very beneficial. In the cooking industry, this can involve the IR scanning of every frozen or non-prepared food having a universal product code, such that a microwave can "read" the information put on the pack. The microwave oven is able to use the time and power instructions that are put on the product by producer. In the laboratory, some UPC codes can be used by the operator to sign some prepared precursor to be heated by the microwave in some clear ways. The device will use an IR sensor to put accurate data in the chemical reactor.

- Greater efficiency of microwave reactions can be obtained by using continuous flow, stop-flow, or large batch (with large power) modes. The type of reactor for microwave synthesis depends on the needs and costs. IHPP PAS developed the MSS2 reactor for hydro- and solvothermal synthesis with stop-flo and also made an added mode-a batch system with a bigger volume of a batch. The bigger volume of batch mode needs to optimize every part of the device and take into consideration the penetration depths of the solvents and materials for each cup/batch/vessel.

- The development of new materials for microwave devices and new types of microwave reactors needs stronger materials with better resistance to high temperature or materials with bigger penetration depth that are not expensive compared with "old used materials" (Section 2.5).

- New devices for the generation plasma in microwave-induced plasma analytical spectrometry (MIC-OES), new types of emission microwave plasma (using semiconductor sources), and induced plasma torches are being developed. More new methods of microwave excitation are being used in the industries, with cheaper methods from known ICP instruments [89].

- Current and future trends in the microwave reactors industry include the following:

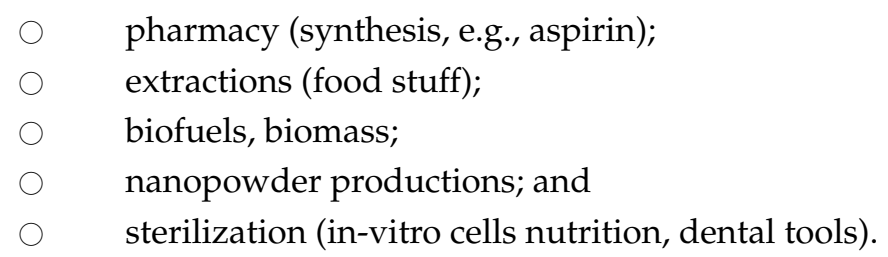

\section{Summary}

In today's world, there are more and more available microwave devices and cheaper components, which have allowed for the wider use of microwaves in laboratories, industries, and households. Knowledge about the operation of microwaves is constantly expanding, which results in greater 
possibilities of synthesis of nanostructures and new materials or the use of microwaves in other industrial applications.

This review shows sources for microwave generation, typical designs and configurations of microwave devices, and the problems of measurements and constructions. The authors focused their attentions on the configurations, materials used for microwave devices, optimized geometries, and solvents with examples of products such as nanopowders. The microwave devices were divided into four groups, depending on the scale, the developed pressure, the temperature for sintering, or other special hybrid or multi-functions.

According to many years of experience in the synthesis of nanomaterials, and construction of microwave reactors, such as MSS1, MSS2 and other works of the Laboratory of Nanostructures, IHPP PAS can distinguish and name the desired special features of microwave reactors in the synthesis and repeatable production of nanoparticles. IHPP PAS claims that the use of microwaves gives the determination of many benefits in the manner and scale of production, as well as in obtaining the characteristic properties of the nanostructures. The most important features for microwave syntheses are as follows:

- Microwave heating allows for better internal heating than conventional techniques, the reaction can be completed right at a selected time or at a specified heating rate, and microwaves create a narrow size distribution of the NPs;

- Microwaves accelerate the synthesis time relative to the conventional method and can result in obtaining a smaller grain size;

- The possibility of stopping the reaction immediately at any time during the reaction is very important, and the temperature continues to decrease in the seconds after stopping the reaction; thus, microwave technology gives a better reaction in controlling this and the ability to easily repeat the results. The example of this type of control is the MSS2 reactor in the stop-flow mode;

- Microwave hydrothermal synthesis is called "green" chemistry because of the use of water as a solvent, and the fact that it allows for the design of chemical products and processes that can reduce or can eliminate the generation of hazardous and dangerous substances. Using chemically inert materials in reactors, such as PTFE or PEEK, to minimalize pollution and facilitate easy cleaning is another way in which it represents "green" chemistry;

- Observing the reflected power during the reaction helps refine the understanding of the structure of changes in the synthesis, and recording and interpreting such data during microwave heating gives more knowledge about the process of the synthesis;

- Metallic particles may be obtained in a microwave reactor (e.g., $\mathrm{Cu}, \mathrm{Ag}$, $\mathrm{Au}$ ), provided that they do not agglomerate and are only in a small quantity. It should be taken into consideration that metals can strongly absorb MW in reactions and create sparking, that is, "arcing".

Author Contributions: S.D., T.C., J.W. and W.Ł. made literature review for this paper. S.D., T.C., J.W. made figures in the text. S.D. wrote the paper.

Funding: The work was supported by the Institute of High Pressure Physics, Polish Academy of Sciences. The modernization of the MSS2 microwave reactor was funded by the project CePT (reference: POIG.02.02.00-14024/08), financed by the European Regional Development Fund within the Operational Programme "Innovative Economy" for 2007-2013.

Acknowledgments: The authors would like to thank Cristina Leonelli for her help and support in writing this review.

Conflicts of Interest: The authors declare no conflicts of interest. 


\section{Abbreviations}

$\begin{array}{ll}\text { HAP } & \text { hydroxyapatite } \\ \text { ICP-MS } & \text { inductively coupled plasma mass spectrometry } \\ \text { ICP-OES } & \text { inductively coupled plasma atomic emission spectroscopy } \\ \text { IHPP PAS } & \text { Institute of High Pressure Physics Polish Academy of Sciences } \\ \text { IR } & \text { infrared } \\ \text { ISM } & \text { industrial, scientific and medical } \\ \text { ITU-R } & \text { International Telecommunication Union Radiocommunications Sector } \\ \text { MIC-OES } & \text { Microwave-induced plasma analytical spectrometry } \\ \text { MW } & \text { microwave } \\ \text { PAEK } & \text { polyaryletherketone } \\ \text { PEEK } & \text { polyetheretherketone } \\ \text { PTFE } & \text { polytetrafluoroethylene } \\ \text { SSA BET } & \text { specific surface area by the BET method } \\ \text { SSS or S } & \text { solid-state source } \\ \text { TWT } & \text { traveling wave tube }\end{array}$

\section{References}

1. Cravotto, G.; Carnaroglio, D. Microwave Chemistry; DeGruyterTextbook; De Gruyter: Berlin, Germany, 2017; ISBN 978-3-11-047993-5.

2. Microwave History. Available online: http://ideafinder.com/history/inventions/microwave.htm (accessed on 10 April 2018).

3. Leadbeater, N.E.; McGowan, C.B. Laboratory Experiments Using Microwave Heating; CRC Press: Boca Raton, FL, USA, 2010.

4. Kitchen, H.J.; Vallance, S.R.; Kennedy, J.L.; Tapia-Ruiz, N.; Carassiti, L.; Harrison, A.; Whittaker, A.G.; Drysdale, T.D.; Kingman, S.W.; Gregory, D.H. Modern microwave methods in solid-state inorganic materials chemistry: From fundamentals to manufacturing. Chem. Rev. 2013, 114, 1170-1206. [CrossRef] [PubMed]

5. General Technical Description of the Magnetron S-Band 750 Kw. Available online: http://njr.com/products / micro/pdf/M1901S.pdf (accessed on 10 April 2018).

6. Industrial Magnetron on Market. Available online: https://alibaba.com/showroom/industrial-magnetron. html (accessed on 10 April 2018).

7. Hartnett, J.P. Advances in Heat Transfer, 1st ed.; Academic Press: New York, NY, USA, 1999; Volume 33.

8. Bandura, A.V.; Lvov, S.N. The Ionization Constant of Water over Wide Ranges of Temperature and Density. J. Phys. Chem. Ref. Data 2006, 35. [CrossRef]

9. Keglevich, G. (Ed.) The spread of the application of the microwave technique in organic synthesis. In Milestones in Microwave Chemistry; Springer: New York, NY, USA, 2016; Chapter 4.

10. Kappe, C.O. Practical Microwave Synthesis for Organic Chemists: Strategies, Instruments, and Protocols; Wiley-VCH Verlag: Weinheim, Germany, 2009. [CrossRef]

11. Patil, N.G.; Benaskar, F.; Rebrov, E.V. Scale-up of Microwave Assisted Flow Synthesis by Transient Processing through Monomode Cavities in Series Schouten. Org. Process Res. Dev. 2014, 18, 1400-1407. [CrossRef]

12. What Is a Gyrotron? Learn about DNP-NMR Spectroscopy. Available online: http://bridge12.com/what-isa-gyrotron/ (accessed on 10 April 2018).

13. Gerling, J.F. Recent Developments in Solid-State Microwave Heating. AMPERE Newslett. 2016, 89, 8-10.

14. Horikoshi, S.; Schiffmann, R.F.; Fukushima, J.; Serpone, N. Microwave Chemical and Materials Processing, 1st ed.; Springer: Singapore, 2018; ISBN 978-981-10-6465-4.

15. Jerby, E. Editorial of the Special Issue on Solid-State Microwave Heating. AMPERE Newslett. 2016, 89, 2-3.

16. Neupane, U.; Rai, R.N. Solid state synthesis of novel charge transfer complex and studies of its crystal structure and optical properties. J. Solid State Chem. 2018, 268, 67-74. [CrossRef]

17. Kiruthigaa, G.; Manoharan, C.; Raju, C.; Jayabharathi, J.; Dhanapandian, S. Solid state synthesis and spectral investigations of nanostructure $\mathrm{SnS}_{2}$. Spectrochim. Acta Part A Mol. Biomol. Spectrosc. 2014, 129, 415-420. [CrossRef] [PubMed] 
18. Leonelli, C.; Veronesi, P. Chapter 2: Microwave Reactors for Chemical Synthesis and Biofuels Preparation. In Production of Biofuels and Chemicals with Microwave, Biofuels and Biorefineries; Fang, Z., Smith, R.L., Jr., Qi, X., Eds.; Springer Science + Business Media: Dordrecht, The Netherlands, 2015; pp. 17-40.

19. Chudoba, T. SHS SiC Synthesis Initiated by Microwaves. Ph.D. Thesis, Akademia Górniczo-Hutnicza im Stanisława Staszica Wydział Inżynierii Materiałowej, Kraków, Poland, 2005.

20. Kappe, C.O. Controlled microwave heating in modern organic synthesis. Angew. Chem. Int. Ed. Engl. 2004, 43, 6250-6284. [CrossRef] [PubMed]

21. Keglevich, G. (Ed.) Interpretation of the Effects of Microwaves. In Milestones in Microwave Chemistry; Springer: New York, NY, USA, 2016; Chapter 1.

22. Sun, J.; Wang, W.; Yue, Q. Review on Microwave-Matter Interaction Fundamentals and Efficient Microwave-Associated Heating Strategies. Materials 2016, 9, 231. [CrossRef] [PubMed]

23. Horikoshi, S.; Serpone, N. Microwave Frequency Effects in Organic Synthesis in Microwaves in Organic Synthesis; Wiley-VCH Verlag: Weinheim, Germany, 2012.

24. Cao, W. (Ed.) Chapter 7: Microwave Apparatus for Kinetic Studies and in-situ Observations in Hydrothermal of High-Pressure. In The Development and Application of Microwave Heating; IntechOpen: London, UK, 2012; ISBN 978-953-51-0835-1.

25. Smith, F.E.; Arsenault, E.A. Microwave-assisted sample preparation in analytical chemistry. Talanta 1996, 43. [CrossRef]

26. Thompson, K.; Booske, J.H.; Cooper, R.F.; Gianchandani, Y.B. Temperature Measurement in Microwave-Heated Silicon Wafers. In Microwaves: Theory and Application in Materials Processing V (Ceramic Transactions); The American Ceramic Society: Westerville, OH, USA, 2000; Volume 111, p. 391.

27. Pert, E.; Carmel, Y.; Birnboim, A.; Olorunyolemi, T.; Gershon, D.; Calame, J.; Lloyd, I.K.; Wilson, O.C., Jr. Temperature Measurements during Microwave Processing: The Significance of Termocouple Effects. J. Am. Ceram. Soc. 2001, 84, 1981-1986. [CrossRef]

28. Whittaker, G.; Mingos, D.M. Arcing and Other Microwave Characteristics of Metal Powders in Liquid Systems. J. Chem. Soc. Dalton Trans. 2000, 1521-1526. [CrossRef]

29. Leonelli, C.; Lojkowski, W. Main development directions in the application of microwave irradiation to the synthesis of nanopowders. Chem. Today 2007, 25, 34-38.

30. Hoz, A.; Díaz-Ortiz, A.; Moreno, A. Review on non-thermal effects of microwave irradiation in organic synthesis. J. Microw. Power Electromagn. Energy 2007, 41, 45-66. [CrossRef]

31. Milestone. Available online: http://milestonesci.com/ (accessed on 10 April 2018).

32. Fang, Z. Production of Biofuels and Chemicals with Microwave; Springer: Dordrecht, The Netherlands, 2014. [CrossRef]

33. Kappe, C.O. How to measure reaction temperature in microwave-heated transformations. Chem. Soc. Rev. 2013, 42, 4977-4990. [CrossRef] [PubMed]

34. Gerling, J.F. Wavegiude Components and Configurations for Optimal Performance. Available online: https:/ / mueggegerling.de/fileadmin/user_upload/muegge.de/Documents/GAE/Technical-References / Waveguide-Components-and-Configurations.pdf/ (accessed on 10 April 2018).

35. Bogdal, D. Microwave-Assisted Organic Synthesis: One Hundred Reaction Procedures, 1st ed.; Elsevier: Amsterdam, The Netherlands, 2005; ISBN 9780080446219.

36. AR-GLAS Schott. Datasheet. Available online: http://us.schott.com/tubing/media/selector/datasheets / english/schott-tubing_datasheet_ar-glas_english.pdf/ (accessed on 10 April 2018).

37. Bilecka, I.; Niederberger, M. Microwave Chemistry for Inorganic Nanomaterials Synthesis. Nanoscale 2010, 2, 1358-1374. [CrossRef] [PubMed]

38. Zhu, Y.-J.; Chen, F. Microwave-Assisted Preparation of Inorganic Nanostructures in Liquid Phase. Chem. Rev. 2014, 114, 6462-6555. [CrossRef] [PubMed]

39. Sibera, D.; Strachowski, T.; Lojkowski, W.; Narkiewicz, U.; Chudoba, T.; Jedrzejewski, R.; Majcher, A.; Presz, A. Nano-ZnAl2O4-Hydrothermal $\mathrm{mw}$ assisted synthesis in a stop-flow reactor and characterization. Probl. Eksploat. 2010, 91-102.

40. Sibera, D.; Jedrzejewski, R.; Mizerack, J.; Presz, A.; Narkiewicz, U.; Lojkowski, W. Synthesis and Characterization of $\mathrm{ZnO}$ Doped with $\mathrm{Fe}_{2} \mathrm{O}_{3}$-Hydrothermal Synthesis and Calcination Process. Acta Phys. Pol. Ser. A 2009, 116. [CrossRef] 
41. Mohammadi, E.; Aliofkhazraei, M.; Hasanpoor, M.; Chipara, M. Hierarchical and Complex ZnO Nanostructures by Microwave-Assisted Synthesis: Morphologies, Growth Mechanism and Classification. Crit. Rev. Solid State Mater. Sci. 2018. [CrossRef]

42. Kołodziejczak-Radzimska, A.; Jesionowski, T. Zinc Oxide-From Synthesis to Application: A Review. Materials 2014, 7, 2833-2881. [CrossRef] [PubMed]

43. Hu, X.L.; Gong, J.M.; Zhang, L.Z.; Yu, J.C. Continuous Size Tuning of Monodisperse ZnO Colloidal Nanocrystal clusters by a Microwave-Polyol Process and Their Application for Humidity Sensing. Adv. Mater. 2008, 20, 4845-4850. [CrossRef]

44. Majcher, A.; Wiejak, J.; Przybylski, J.; Chudoba, T.; Wojnarowicz, J. A Novel Reactor for Microwave Hydrothermal Scale-up Nanopowder Synthesis. Int. J. Chem. React. Eng. 2013, 11, 361-368. [CrossRef]

45. Wojnarowicz, J.; Opalinska, A.; Chudoba, T.; Gierlotka, S.; Mukhovskyi, R.; Pietrzykowska, E.; Sobczak, K.; Lojkowski, W. Effect of water content in ethylene glycol solvent on the size of $\mathrm{ZnO}$ nanoparticles prepared using microwave solvothermal synthesis. J. Nanomater. 2016, 2016, 2789871. [CrossRef]

46. Wojnarowicz, J.; Chudoba, T.; Koltsov, I.; Gierlotka, S.; Dworakowska, S.; Lojkowski, W. Size control mechanism of $\mathrm{ZnO}$ nanoparticles obtained in microwave solvothermal synthesis. Nanotechnology 2018, 29, 065601. [CrossRef]

47. Wojnarowicz, J.; Chudoba, T.; Smoleń, D.; Łojkowski, W.; Majcher, A.; Mazurkiewicz, A. Examples of the Nanoparticles Produced by Microwave Solvothermal Synthesis (MSS) Route. Glass Ceram. 2014, 6, 8-11.

48. Wojnarowicz, J.; Kusnieruk, S.; Chudoba, T.; Gierlotka, S.; Lojkowski, W.; Knoff, W.; Lukasiewicz, M.I.; Witkowski, B.S.; Wolska, A.; Klepka, M.T.; et al. Paramagnetism of cobalt-doped ZnO nanoparticles obtained by microwave solvothermal synthesis. Beilstein J. Nanotechnol. 2015, 6, 1957-1969. [CrossRef] [PubMed]

49. Wojnarowicz, J.; Mukhovskyi, R.; Pietrzykowska, E.; Kusnieruk, S.; Mizeracki, J.; Lojkowski, W. Microwave solvothermal synthesis and characterization of manganese-doped ZnO nanoparticles. Beilstein J. Nanotechnol. 2016, 7, 721-732. [CrossRef] [PubMed]

50. Wojnarowicz, J.; Chudoba, T.; Gierlotka, S.; Sobczak, K.; Lojkowski, W. Size Control of Cobalt-Doped ZnO Nanoparticles Obtained in Microwave Solvothermal Synthesis. Crystals 2018, 8, 179. [CrossRef]

51. Lojkowski, W.; Gedanken, A.; Grzanka, E.; Opalinska, A.; Strachowski, T.; Pielaszek, R.; Tomaszewska-Grzeda, A.; Yatsunenko, S.; Godlewski, M.; Matysiak, H.; et al. Solvothermal synthesis of nanocrystalline zinc oxide doped with $\mathrm{Mn}^{2+}, \mathrm{Ni}^{2+}, \mathrm{Co}^{2+}$ and $\mathrm{Cr}^{3+}$ ions. J. Nanopart. Res. 2009, 11, 1991-2002. [CrossRef]

52. Wojnarowicz, J.; Kuśnieruk, S.; Chudoba, T.; Mizeracki, J.; Łojkowski, W. Microwave solvothermal synthesis of Co-doped ZnO nanoparticles. Glass Ceram. 2015, 3, 8-13.

53. Fidelus, J.; Piticescu, R.; Piticescu, R.; Lojkowski, W.; Giurgiu, L. Solvothermal Synthesis of Co-doped ZnO Nanopowders. Zeitschrift fur Naturforschung B 2008, 63, 725-729. [CrossRef]

54. Branka, H.; Romcevic, N.; Maja, R.; Kuryliszyn-Kudelska, I.; Dobrowolski, W.; Narkiewicz, U.; Sibera, D. Raman study of surface optical phonons in $\mathrm{ZnO}(\mathrm{Co})$ nanoparticles prepared by hydrothermal method. Hem. Ind. 2013, 67, 695-701. [CrossRef]

55. Wojnarowicz, J.; Chudoba, T.; Gierlotka, S.; Lojkowski, W. Effect of Microwave Radiation Power on the Size of Aggregates of ZnO NPs Prepared Using Microwave Solvothermal Synthesis. Nanomaterials 2018, 8, 343. [CrossRef] [PubMed]

56. Corradi, A.B.; Bondioli, F.; Ferrari, A.M.; Focher, B.; Leonelli, C. Synthesis of silica nanoparticles in a continuous-flow microwave reactor. Powder Technol. 2006, 167, 45-48. [CrossRef]

57. Cabello, G.; Davoglio, R.A.; Pereira, E.C. Microwave-assisted synthesis of anatase- $\mathrm{TiO}_{2}$ nanoparticles with catalytic activity in oxygen reduction. J. Electroanal. Chem. 2017, 794, 36-42. [CrossRef]

58. Ebadzadeh, T.; Asadian, K. Microwave-assisted synthesis of nanosized $\alpha-\mathrm{Al}_{2} \mathrm{O}_{3}$. Powder Technol. 2009, 192, 242-244. [CrossRef]

59. Shi, S.; Deng, T.; Zhang, M.; Yang, G. Fast facile synthesis of $\mathrm{SnO}_{2} /$ Graphene composite assisted by microwave as anode material for lithium-ion batteries. Electrochim. Acta 2017, 246, 1104-1111. [CrossRef]

60. Zhong, Y.; Yu, L.; Chen, Z.-F.; He, H.; Ye, F.; Cheng, G.; Zhang, Q. Microwave-Assisted Synthesis of $\mathrm{Fe}_{3} \mathrm{O}_{4}$ Nanocrystals with Predominantly Exposed Facets and Their Heterogeneous UVA/Fenton Catalytic Activity. ACS Appl. Mater. Interfaces 2017, 9, 29203-29212. [CrossRef] [PubMed]

61. Horikoshi, S.; Serpone, N. Microwaves in Nanoparticle Synthesis: Fundamentals and Applications; Wiley-VCH Verlag: Weinheim, Germany, 2013; ISBN 9783527331970. [CrossRef] 
62. Malka, I.; Danelska, A.; Kimmel, G. The Influence of $\mathrm{Al}_{2} \mathrm{O}_{3}$ Content on $\mathrm{ZrO}_{2}-\mathrm{Al}_{2} \mathrm{O}_{3}$ Nanocomposite Formation-The Comparison between Sol-Gel and Microwave Hydrothermal Methods. Mater. Today Proc. 2016, 3, 2713-2724. [CrossRef]

63. Koltsov, I.; Smalc-Kozirowska, J.; Prześniak-Welenc, M.; Małysa, M.; Kimmel, G.; McGlynn, J.; Ganin, A.; Stelmakh, S. Mechanism of reduced sintering temperature of $\mathrm{Al}_{2} \mathrm{O}_{3}-\mathrm{ZrO}_{2}$ nanocomposites obtained by microwave hydrothermal synthesis. Materials 2018, 11, 829. [CrossRef] [PubMed]

64. Koltsov, I.; Prześniak-Welenc, M.; Wojnarowicz, J.; Rogowska, A.; Mizeracki, J.; Malysa, M.; Kimmel, G. Thermal and physical properties of $\mathrm{ZrO}_{2}-\mathrm{AlO}(\mathrm{OH})$ nanopowders synthesised by microwave hydrothermal method. J. Therm. Anal. Calorim. 2018, 131, 2273-2284. [CrossRef]

65. Smoleń, D.; Chudoba, T.; Gierlotka, S.; Kedzierska, A.; Łojkowski, W.; Sobczak, K.; Święszkowski, W.; Kurzydłowski, K.J. Hydroxyapatite Nanopowder Synthesis with a Programmed Resorption Rate. J. Nanomater. 2012, 2012, 841971. [CrossRef]

66. Kuśnieruk, S.; Wojnarowicz, J.; Chodara, A.; Chudoba, T.; Gierlotka, S.; Lojkowski, W. Influence of hydrothermal synthesis parameters on the properties of hydroxyapatite nanoparticles. Beilstein J. Nanotechnol. 2016, 7, 1586-1601. [CrossRef] [PubMed]

67. Opalinska, A.; Malka, I.; Dzwolak, W.; Chudoba, T.; Presz, A.; Lojkowski, W. Size-dependent density of zirconia nanoparticles. Beilstein J. Nanotechnol. 2015, 6, 27-35. [CrossRef] [PubMed]

68. Lojkowski, W.; Leonelii, C.; Chudoba, T.; Wojnarowicz, J.; Majcher, A.; Mazurkiewicz, A. High-Energy-Low-Temperature Technologies for the Synthesis of Nanoparticles: Microwaves and High Pressure. Inorganics 2014, 2, 606-619. [CrossRef]

69. Opalinska, A.; Leonelli, C.; Lojkowski, W.; Pielaszek, R.; Grzanka, E.; Chudoba, T.; Matysiak, H.; Wejrzanowski, T.; Kurzydlowski, K.J. Effect of pressure on synthesis of Pr-doped Zirconia powders produced by microwave-driven hydrothermal reaction. J. Nanomater. 2006, 2006, 98769. [CrossRef]

70. Yoshimura, M.; Byrappa, K. Hydrothermal processing of materials: Past, present and future. J. Mater. Sci. 2008, 43, 2085-2103. [CrossRef]

71. Varma, R.S. Green Chemistry with Microwave Energy. In Innovations in Green Chemistry and Green Engineering; Anastas, P., Zimmerman, J., Eds.; Springer: New York, NY, USA, 2013.

72. Ravichandran, S.; Karthikeyan, E. Microwave Synthesis-A Potential Tool for Green Chemistry. Int. J. Chem. Tech. Res. 2011, 3, 466-470.

73. Zovinka, E.P.; Stock, A.E. Microwave Instruments: Green Machines for Green Chemistry? J. Chem. Educ. 2010, 87, 350-352. [CrossRef]

74. Morschhäuser, R.; Krull, M.; Kayser, C.; Boberski, C.; Bierbaum, R.; Püschner, P.A.; Glasnov, T.N.; Kappe, C.O. Microwave-assisted continuous flow synthesis on industrial scale. Green Process. Synth. 2012, 1, 281-290. [CrossRef]

75. Tierney, J.; Lidstrom, P. Microwave Assisted Organic Synthesis; Blackwell Publishing Ltd.: Hoboken, NJ, USA, 2005; ISBN 1-4051-1560-2. [CrossRef]

76. Galema, S.A. Microwave Chemistry. Chem. Soc. Rev. 1997, 26, 233-238. [CrossRef]

77. Bogdal, D.; Lukasiewicz, M.; Bednarz, S. Microwave induced thermal gradients in solventless reaction systems. Tetrahedron 2006, 62, 9440-9445. [CrossRef]

78. Bogdal, D.; Prociak, A. Microwave-Enhanced Polymer Chemistry and Technology; Blackwell Publishing: Hoboken, NJ, USA, 2007.

79. Dworakowska, S.; Bogdał, D.; Prociak, A. Microwave-Assisted Synthesis of Polyols from Rapeseed Oil and Properties of Flexible Polyurethane Foams. Polymers 2012, 4, 1462-1477. [CrossRef]

80. Kappe, C.O.; Stadler, A.; Dallinger, D. Microwaves in Organic and Medicinal Chemistry; Wiley-VCH Verlag: Weinheim, Germany, 2012; Volume 52.

81. Chemat, F.; Cravotto, G. (Eds.) Microwave-Assisted Extraction for Bioactive Compounds Theory and Practice; Springer Science + Business Media: New York, NY, USA, 2013; ISBN 978-1-4614-4829-7. [CrossRef]

82. Wathey, B.; Tierney, J.; Lidstrom, P.; Westman, J. The Impact of Microwave-Assisted Organic Chemistry on Drug Discovery. Drug Discov. Today 2002, 7, 373-380. [CrossRef]

83. Fang, Z.; Smith, R.L., Jr.; Qi, X. (Eds.) Production of Biofuels and Chemicals with Microwave Tom 3 Biofuels and Biorefineries; Springer: New York, NY, USA, 2014; ISBN 9789401796125. [CrossRef]

84. Cravotto, G.; Cintas, P. The Combined Use of Microwaves and Ultrasound: Improved Tools in Process Chemistry and Organic Synthesis. Chemistry 2007, 13, 1902-1909. [CrossRef] [PubMed] 
85. Leonelli, C.; Mason, T.J. Microwave and ultrasonic processing: Now a realistic option for industry. Chem. Eng. Process. Process Intensif. 2010, 49, 885-900. [CrossRef]

86. Klána, P.; Hájek, M.; Církva, V. The electrodeless discharge lamp: A prospective tool for photochemistry: Part 3. The microwave photochemistry reactor. J. Photochem. Photobiol. A Chem. 2001, 140, 185-189. [CrossRef]

87. Rizzuti, A.; Leonelli, C. Crystallization of aragonite particles from solution under microwave irradiation. Powder Technol. 2008, 186, 255-262 101016/jpowtec200712012. [CrossRef]

88. Leonelli, C.; Veronesi, P.; Denti, L.; Gatto, A.; Iuliano, L. Microwave assisted sintering of green metal parts. J. Mater. Process. Technol. 2008, 205, 489-496. [CrossRef]

89. Jankowski, K.J.; Reszke, E. Microwave Induced Plasma Analytical Spectrometry; RSC Publishing: London, UK, 2011.

(C) 2018 by the authors. Licensee MDPI, Basel, Switzerland. This article is an open access article distributed under the terms and conditions of the Creative Commons Attribution (CC BY) license (http:/ / creativecommons.org/licenses/by/4.0/). 